VICENZI, R.K.F. et al. Rentabilidade e lucratividade das culturas temporárias e permanentes.

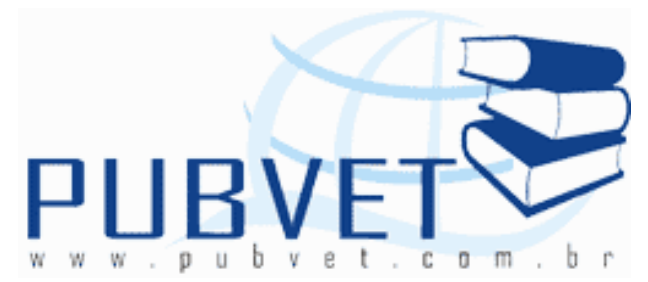

PUBVET, Publicações em Medicina Veterinária e Zootecnia.

\title{
Rentabilidade e lucratividade das culturas temporárias e permanentes
}

Raquel Kramer da Fonseca Vicenzi ${ }^{1}$; Sérgio Cavagnoli Guth ${ }^{2}$; Marta Elisete Ventura da Motta ${ }^{3}$; Maria Emilia Camargo ${ }^{4}$; Rosecler Maschio Giliol ${ }^{5}$; Maria Teresa Martiningui Pacheco ${ }^{6}$

${ }^{1}$ Bacharel em Ciências Contábeis - Universidade de Caxias do Sul, RS

${ }^{2}$ Mestre em Economia - Universidade de Caxias do Sul, RS

${ }^{3}$ Doutoranda em Administração - Universidade de Caxias do Sul, RS

${ }^{4}$ Doutora em Engenharia de Produção - PPGA - Universidade de Caxias do Sul, RS

${ }^{5}$ Mestre em Administração - Universidade de Caxias do Sul, RS

${ }^{6}$ Especialista em Controladoria - Universidade de Caxias do Sul, RS

\section{Resumo}

Este trabalho tem por objetivo desenvolver um estudo que busca identificar as particularidades das culturas temporárias e permanentes e através da mensuração de dados financeiros e econômicos de produtores que trabalham com o cultivo de três culturas - alho, soja e maçã - possibilitando, assim, a determinação da lucratividade e rentabilidade de cada uma, dando condições ao produtor de ter dados suficientes para decidir sobre qual delas explorar. Neste estudo, inicialmente, foi realizada uma abordagem teórica das culturas para dar sustentação ao desenvolvimento dos cálculos de Valor Presente Líquido (VPL), Taxa Interna de Retorno (TIR) e Ebitda. Os dados utilizados 
VICENZI, R.K.F. et al. Rentabilidade e lucratividade das culturas temporárias e permanentes. PUBVET, Londrina, V. 6, N. 9, Ed. 196, Art. 1313, 2012.

para a realização dos cálculos, resultaram da observação e coleta de dados com entidades representativas de classe e produtores da região nordeste do estado do Rio Grande do Sul. Os resultados da aplicação dos métodos de VPL e TIR no estudo das três culturas, contemplando apenas quatro safras, indicaram que o alho seria mais viável economicamente. A maçã apresentou viabilidade, porém com a Taxa Mínima de Atratividade (TMA) abaixo da préestabelecida e a soja apresentou VPL e TIR negativos. Porém, considerando o Ebitda, a soja teve uma maior lucratividade.

Palavras-chave: culturas temporárias; culturas permanentes; rentabilidade; lucratividade; métodos.

\section{Rentability and profitability of temporary and permanent crops}

This work aims to develop a study that seeks to identify the particularities of temporary and permanent crops and by measuring the financial and economic producers who work with the cultivation of three crops - garlic, soy and apple thus enabling the determination rentability and profitability of each one, giving the producer able to have enough data to decide which one to explore. This study was initially carried out a theoretical approach of crops to sustain the development of the calculations of Net Present Value (VPL), Internal Rate of Return (TIR) and Ebitda. The data used fot the calculations, results of observation and data collection with entities representing the producers and the northeastern state of Rio Grande do Sul. The results of applying the methods of VPL and TIR in the study of three cultures, comprising only four seasons, indicated that garlic would be more economically viable. The apple was viable, but below the Minimum Rate of Attractiveness (TMA) below the pre-established and soybeans had negative NPV and IRR. However, considering the Ebitda, soybeans had greater profitability.

Keywords: temporary crops; permanent crops; rentability; profitability; methods. 
VICENZI, R.K.F. et al. Rentabilidade e lucratividade das culturas temporárias e permanentes.

PUBVET, Londrina, V. 6, N. 9, Ed. 196, Art. 1313, 2012.

\section{INTRODUÇÃO}

$\mathrm{Na}$ agricultura, as culturas temporárias e permanentes possuem características que as diferenciam e, uma delas é a colheita. Nas culturas temporárias ocorre apenas uma colheita e nas permanentes ocorrem mais de uma colheita. E, como saber então qual é a mais rentável e qual oferece uma lucratividade maior para o produtor.

Para decidir em qual cultura, temporária ou permanente, investir o produtor tem que ter ciência de todas as variáveis e características, apresentadas de uma forma coerente que possa propiciar tal decisão. Este trabalho, portanto, tem o objetivo de estudar a lucratividade e a rentabilidade da produção de alho, soja e maçã.

Para realizar este estudo foi projetada uma área com 120 hectares de terras agricultáveis e com base em dados econômicos e financeiros, foram analisados quatro anos agrícolas, sendo utilizados dados históricos de três anos, safra de 2007, 2008 e 2009 e um ano projetado. Através de cálculos financeiros, levando em consideração os critérios de Valor Presente Líquido (VPL) e Taxa Interna de Retorno (TIR) foi elucidada a rentabilidade e o critério Ebitda utilizado para evidenciar a lucratividade.

Para a gestão da atividade rural o produtor tem condições de utilizar ferramentas que o auxilie em suas decisões, inclusive, na decisão de o que produzir. Neste caso específico, decidir se é melhor trabalhar com cultura temporária ou permanente. Com o auxilio da administração, o produtor poderá contar com técnicas de planejamento e orçamento financeiro, estes baseados em dados fornecidos pela contabilidade.

Neste trabalho, procurou-se identificar qual a lucratividade e a rentabilidade resultantes do cultivo das culturas de alho, da soja e da maçã, para isso precisou-se da alocação das receitas, dos custos e despesas e enfim, as variáveis que possam servir para a efetivação dos cálculos, através de métodos apropriados. A identificação dessas variáveis está baseada em dados que são fornecidos pela contabilidade. 
VICENZI, R.K.F. et al. Rentabilidade e lucratividade das culturas temporárias e permanentes.

PUBVET, Londrina, V. 6, N. 9, Ed. 196, Art. 1313, 2012.

Neste contexto, através deste estudo, o produtor rural poderá adquirir uma base consistente e ter condições de mensurar qual é a melhor cultura, temporária ou permanente, para investir.

\section{REFERENCIAL TEÓRICO}

Neste item, são evidenciados os conceitos e as características que envolvem a atividade e a administração rural, além de proporcionar o conhecimento sobre as diferenças existentes entre as culturas temporárias e permanentes.

\subsection{Culturas Temporárias}

As culturas temporárias, de acordo com Marion (2010) são aquelas que oferecem apenas uma colheita e sujeitas ao replantio, normalmente, o período de vida é curto.

Para Crepaldi (2011) culturas temporárias são aquelas sujeitas ao replantio a cada colheita. Elas são arrancadas do solo para que seja feito novo plantio, como é o caso do milho, da soja, do feijão, do alho, entre outras. Esse tipo de cultura, conforme Marion (2010), também, é conhecida como anual.

Como exemplos de culturas temporárias têm-se a soja, o trigo, o milho, o alho, a cebola, entre outras. Este trabalho trata de três culturas: soja transgênica, alho e maçã. Destas, duas são temporárias, que é o caso da soja e do alho. A seguir são abordadas as características dessas culturas.

\subsubsection{Soja}

O desenvolvimento da soja no Brasil, de acordo com Bonato e Bonato (1987) iniciou-se em 1882, quando os primeiros materiais genéticos foram introduzidos e testados no Estado da Bahia. Foi em 1900, segundo a EMBRAPA (2004) que a soja foi testada no estado do Rio Grande do Sul, onde as condições climáticas são similares àquelas prevalentes na região de origem dos materiais avaliados, que eram do sul dos Estados Unidos. 
VICENZI, R.K.F. et al. Rentabilidade e lucratividade das culturas temporárias e permanentes. PUBVET, Londrina, V. 6, N. 9, Ed. 196, Art. 1313, 2012.

O verdadeiro estímulo à produção em larga escala da soja no Brasil, foi dado em meados dos anos 50, que segundo a EMBRAPA (2004), com a decisão oficial de prover incentivos fiscais à produção do trigo, a cultura da soja foi beneficiada, também, pois era considerada a melhor alternativa de verão para suceder o trigo cultivado no inverno, multiplicando por cinco o volume de soja produzido.

Foi na década de 1970 que a produção de soja mais cresceu e se consolidou como a principal lavoura do agronegócio brasileiro. A produção que era de 1,5 milhões de toneladas no ano de 1970, passou a ser de 58,2 milhões de toneladas, na safra 2008/09 conforme dados da Epagri/Cepa (2009/2010).

A EMBRAPA (2004, p.21) coloca que "a revolução sócio-econômica e tecnológica protagonizada pela soja no Brasil Moderno, pode ser comparada ao fenômeno ocorrido com a cana-de-açúcar, no Brasil Colônia e com o café, no Brasil Império/República que, em épocas diferentes, comandaram o comércio exterior do País".

Este explosivo crescimento da produção de soja no País determinou, segundo a EMBRAPA (2004), uma cadeia de mudanças sem precedentes na sua história. A soja foi responsável por inúmeros avanços na agricultura brasileira. Por exemplo, com o desenvolvimento da produção de soja houve o surgimento da agricultura comercial no Brasil e a aceleração da mecanização das lavouras brasileira, sem considerar, ainda a modernização do setor de transportes, a modificação e enriquecimento da dieta alimentar dos brasileiros, dentre outras mudanças consideráveis.

A soja, segundo a EMBRAPA (2004), tem importante contribuição para o funcionamento, sobretudo, de duas cadeias produtivas agroindustriais do país: aves (corte e postura) e suínos. Com isso, a oleaginosa contribui, principalmente de forma indireta, para a geração de empregos nessas duas cadeias produtivas, que de acordo com informações da Embrapa Suínos e Aves, são responsáveis pelo emprego de mais de um milhão de pessoas.

A cadeia produtiva da soja é, de acordo com estudos do Ministério da Agricultura, Pecuária e Abastecimento - MAPA (2010), de suma importância 
VICENZI, R.K.F. et al. Rentabilidade e lucratividade das culturas temporárias e permanentes. PUBVET, Londrina, V. 6, N. 9, Ed. 196, Art. 1313, 2012.

para a economia brasileira. As exportações de soja de acordo com projeção da Associação de Gestão Estratégica alcançarão 37,87 milhões de toneladas. Representam um aumento de 10,3 milhões $t$ em relação à quantidade exportada pelo Brasil em 2008/2009. Ainda segundo MAPA (2010, p. 22) a taxa anual projetada para exportação de soja em grão é de $2,87 \%$, quase igual à taxa mundial projetada pelo MAPA/Fapri (2009) para os próximos anos. Além disso, a soja destaca-se como a principal cultura explorada no mercado interno, respondendo por cerca de 55\% da produção brasileira de grãos. Em nível mundial, o País já é o segundo maior produtor, atrás apenas dos Estados Unidos, e o maior exportador.

\subsubsection{Alho}

O alho (Allium sativum L.), de acordo com a Empresa Brasileira de Pesquisa Agropecuária - EMBRAPA (1993), é uma planta aromática da família das Alliaceae, a mesma da cebola. O porte dessa planta varia entre 50 e $70 \mathrm{~cm}$ de altura, dependendo da variedade, e suas raízes atingem até $50 \mathrm{~cm}$ de profundidade. Suas folhas estreitas e alongadas são recobertas por uma camada de cera que as protege do ataque de muitas doenças.

O alho, por sua característica de condimento, é um produto de demanda inelástica em relação à renda. O consumo nacional, ou seja, a demanda aparente passou de 400 gramas/habitante/ano na década de 1980 para 1,26 quilos em 2010 (EPAGRI/CEPA/SC, 2009/2010). A evolução do consumo restringe-se basicamente ao crescimento vegetativo da população.

Em termos de Brasil, a cultura do alho é praticada em quase todo território nacional. A EPAGRI/CEPA/SC (2009/2010) informa que, nas safras de 2006 a 2009, as áreas de cultivo mostram um comportamento similar, ao redor dos dez mil hectares. Nesse período, o que cresceu foi a produtividade média, que passou de 8,36 toneladas por hectare em 2006 para 9,92 toneladas em 2010.

De acordo com o EPAGRI/CEPA/SC (2009/2010), O Brasil tem-se caracterizado como um tradicional importador de alho. "Existem no mundo 
VICENZI, R.K.F. et al. Rentabilidade e lucratividade das culturas temporárias e permanentes. PUBVET, Londrina, V. 6, N. 9, Ed. 196, Art. 1313, 2012.

quatro grandes centros de produção de alho: asiático, europeu, norteamericano e sul-americano". A China se destaca como maior produtor, consumidor e exportador mundial. O país asiático plantou 779,2 mil hectares, colheu $17.967,9$ mil toneladas, representando $80 \%$ da produção mundial. No centro europeu, destaca-se a Espanha, com área plantada em 2009 de 16 mil hectares, colheu 154 mil toneladas. No centro norte-americano produz basicamente para os Estados Unidos e México. No centro sul-americano o destaque é a Argentina, maior exportador regional de alho, cultivou 13.937 hectares e colheu 120.391 toneladas, das quais 75\% destinadas ao Brasil, sendo o segundo maior importador mundial desse bulbo.

Esta subordinação do país ao alho importado para a garantia da normalidade do abastecimento interno tem ampliado, segundo informações da EPAGRI (2002), de forma bastante significativa nos últimos anos; especialmente nos três últimos anos, devido à gradativa alternância da área plantada para a cultura em território brasileiro e, como conseqüência, a substantiva redução da produção nacional.

A nova safra brasileira de alho, segundo a EPAGRI/CEPA/SC (2009/2010), indica um pequeno aumento nas áreas de cultivo do alho em todo o país estimado em 3,74\% para 2010. Esse aumento é em decorrência do bom resultado econômico das últimas três safras, quando os preços foram remuneradores.

A EPAGRI (2002) coloca que de acordo com as últimas pesquisas de avaliação das safras agrícolas brasileiras, recentemente promovidas pelo IBGE nos mais diferentes estados brasileiros produtores de alho, o total da produção a ser colhido no país está estimado em um valor 3,2\% inferior ao obtido na safra 2006/07.

A EPAGRI (2002) alerta que enquanto os números projetados para a atividade em nível nacional continuam a se apresentar instáveis, os indicadores das importações brasileiras do produto mostram-se em constante crescimento, pois conforme dito anteriormente é preciso atender a demanda nacional pelo produto. 
VICENZI, R.K.F. et al. Rentabilidade e lucratividade das culturas temporárias e permanentes.

PUBVET, Londrina, V. 6, N. 9, Ed. 196, Art. 1313, 2012.

\subsection{CULTURAS PERMANENTES}

As culturas permanentes diferem-se das temporárias. As culturas permanentes caracterizam-se por oferecer mais de uma colheita ou produção (Marion, 2010). Na visão de Crepaldi (2011) as culturas permanentes são aquelas que propiciam várias colheitas, sem a necessidade de serem replantadas.

Como exemplo de cultura permanente, temos os pomares. Marion (2010, p. 16) coloca que "normalmente atribui-se às culturas permanentes uma duração mínima de quatro anos" e que dentro do seu ponto de vista basta que a cultura tenha duração de mais de um ano e propiciar mais de uma colheita para ser considerada permanente.

\subsubsection{Maçã}

A Empresa Brasileira de Pesquisa Agropecuária - EMBRAPA (2004, p. 10) afirma que a maçã "é a fruta de clima temperado mais importante comercializada como fruta fresca, tanto no contexto internacional quanto no nacional".

Segundo dados da Associação Brasileira dos Produtores de Maçã - ABPM (2005) o cultivo da macieira é recente no Brasil e estabeleceu-se por meio de grandes empresas atraídas por incentivos de políticas públicas. A entidade esclarece que até a década de 60, somente a Região de Valinhos (SP) tinha alguns pomares comerciais, cultivados com variedades de baixo valor comercial, cuja produção era vendida em caixas de tomate.

A produção de maçã, de acordo com dados da ABPM (2009) está concentrada na Região Sul do Brasil, que é responsável por praticamente $99 \%$ (noventa e nove por cento) da produção nacional. O estado com maior produção é o de Santa Catarina com $51 \%$, seguido pelo Rio Grande do Sul com $44 \%$ e do Paraná com 5\%. São Paulo, Minas Gerais e Bahia são poucos representativos com menos de $1 \%$ e normalmente não constam das estatísticas, comenta o presidente da ABPM Sr. Pierre Nicolas Peres. "O 
VICENZI, R.K.F. et al. Rentabilidade e lucratividade das culturas temporárias e permanentes. PUBVET, Londrina, V. 6, N. 9, Ed. 196, Art. 1313, 2012.

principal mercado consumidor, segundo a ABPM, é o estado de São Paulo, onde a maior oferta do produto ocorre no mês de fevereiro".

Os três grandes pólos produtores de maçã no Brasil são Vacaria (RS), São Joaquim (SC) e Fraiburgo (SC), segundo dados da ABPM (2009).

A produção brasileira de maçã teve um significativo crescimento a partir da década de 70 e isto ocorreu segundo a ABPM em função da estratégia dos produtores que sempre foi de explorar o que de melhor a maçã brasileira tem, ou seja, o sabor e o aspecto voltado à saúde, além da oferta de 1,5 empregos diretos para cada hectare plantado. A maçã, por sua vez, respondeu com bom desempenho e tornou-se uma fruta acessível ao poder aquisitivo do brasileiro e, hoje, faz parte da sua dieta alimentar, o que a transformou em um alimento popular, resultando na evolução do consumo e conseqüente aumento da produção.

Do ano de 1985 ao ano de 2005, segundo dados do Instituto Brasileiro de Geografia e Estatística (IBGE), o consumo interno "per capita" de maçã, passou de 2,22kg/habitante/ano para 4,03 kg/habitante/ano, sendo considerado satisfatório se comparado aos anos iniciais do desenvolvimento da produção de maçã no Brasil.

A evolução da balança comercial da maçã, onde pode ser verificado que a partir do ano de 2002 o saldo sempre se apresentou positivo. A ABPM destaca que em menos de três décadas, de importador líquido, o Brasil transformou-se em um dos grandes exportadores mundiais de maçã e que no ano de 2004 a maçã foi a fruta comercializada in natura que mais divisas trouxe ao Brasil. Ainda segundo a ABPM (2009), o ano de 2008, apesar de não ter repetido 2004 em volume foi a temporada que registrou o maior faturamento de todos os tempos com a exportação.

Diante deste contexto torna-se importante aos produtores 0 conhecimento de qual lucro sua atividade gera e como conseqüência o quanto está sendo agregado de rentabilidade no negócio. 
VICENZI, R.K.F. et al. Rentabilidade e lucratividade das culturas temporárias e permanentes.

PUBVET, Londrina, V. 6, N. 9, Ed. 196, Art. 1313, 2012.

\subsection{Lucratividade e Rentabilidade}

De uma forma bem prática, pode-se definir lucratividade como o percentual de ganho obtido sobre as vendas realizadas e a rentabilidade indica o percentual de remuneração do capital investido. Entre os indicadores de desempenho destas estão o Ebitda para a lucratividade, o Valor Presente Líquido (VPL) e a Taxa Interna de Retorno (TIR) para a rentabilidade.

\subsubsection{EBTIDA}

Nos últimos anos, conforme Zaffani (2005), um indicador passou a ser amplamente utilizado pelas empresas de capital aberto e pelos analistas de mercado como a principal, e às vezes única, avaliação de desempenho e/ou do valor das companhias: o EBITDA.

A sigla EBITDA corresponde ao "Earning Before Interests, Taxes, Depreciation and Amortization" que, em português significa "Lucro Antes dos Juros, Impostos, Depreciação e Amortização", conhecido como LAJIDA. Zaffani (2005) diz que "muito embora o EBITDA também seja chamado de Fluxo de Caixa Operacional (Operational Cash Flow), o mesmo leva em conta apenas o desempenho operacional da empresa e não reflete o impacto no resultado dos itens extraordinários, das despesas como investimentos e das mudanças havidas no capital de giro".

\subsubsection{Valor presente líquido}

Para Kassai et. al. (2000) o Valor Presente Líquido (VPL) é "um dos instrumentos sofisticados mais utilizados para se avaliar propostas de investimentos de capital", isto porque este método reflete a riqueza em valores monetários do investimento medida pela diferença entre o valor presente das entradas de caixa e o valor presente das saídas de caixa, a uma determinada taxa de desconto, chamada da Taxa Mínima de Atratividade.

Entende-se por Taxa Mínima de Atratividade (TMA) a taxa mínima a ser alcançada em determinado projeto; caso contrário, o mesmo deve ser rejeitado. É, também, a taxa utilizada para descontar os fluxos de caixa 
VICENZI, R.K.F. et al. Rentabilidade e lucratividade das culturas temporárias e permanentes.

PUBVET, Londrina, V. 6, N. 9, Ed. 196, Art. 1313, 2012.

quando se usa o método do valor presente líquido (VPL) e o parâmetro de comparação para a TIR. É o rendimento mínimo de uma segunda melhor alternativa do mercado. (KASSAI, et. al., 2000)

Assaf Neto (2003) explica que a medida do VPL é obtida pela diferença entre o valor presente dos benefícios líquidos de caixa, previstos para cada período do horizonte de duração do projeto, e o valor presente do investimento (desembolso de caixa).

\subsubsection{Taxa interna de retorno}

O método da taxa interna de retorno (TIR) segundo Assaf Neto (2003) representa a taxa de desconto que iguala, em determinado momento, as entradas com as saídas previstas de caixa. O cálculo da TIR requer, basicamente, o conhecimento dos montantes de dispêndio de capital e dos fluxos de caixa líquidos incrementais gerados pela decisão.

$\mathrm{Na}$ visão de Kassai et. al. (2000) a TIR é uma das formas mais sofisticadas de avaliar propostas de investimentos de capital e, completa dizendo que a TIR representa a taxa de desconto que igual, em um único momento os fluxos de entrada com os de saída de caixa. Em resumo, é a taxa que resulta em um VPL igual a zero.

Assaf Neto (2003) considera que se esses valores ocorrerem em diferentes momentos pode-se afirmar que a TIR, ao levar em conta o valor do dinheiro no tempo, representa a rentabilidade do projeto expressa em termos de taxa de juros composta equivalente periódica.

\section{METODOLOGIA DA PESQUISA}

Marconi e Lakatos (1996, p. 16) colocam que "a pesquisa têm importância fundamental no campo das ciências sociais, principalmente na obtenção de soluções para problemas coletivos". Dentro dessa linha de pensamento este trabalho tem o intuito de resolver um problema, através de uma pesquisa exploratória, que contempla a busca em bibliografia pertinente e um estudo de caso. 
VICENZI, R.K.F. et al. Rentabilidade e lucratividade das culturas temporárias e permanentes. PUBVET, Londrina, V. 6, N. 9, Ed. 196, Art. 1313, 2012.

Uma vez realizada a fundamentação teórica pertinente ao tema em questão, a tarefa passa a ser a de especificar os caminhos metodológicos que esta pesquisa pretendeu perseguir, assim como a definição da natureza do estudo e a escolha do método.

Para a concretização do estudo de caso foram realizadas observações, coleta de dados e informações, com entidades que apoiam os produtores atuantes com as três culturas. Para o estudo do alho, por exemplo, foram utilizadas informações do Instituto Cepa, do Estado de Santa Catarina e da EPAGRI, porém, já no caso da soja, foram utilizadas informações da EPAGRI e da Cooperativa Tritícola Mista Vacariense (COOPERVAL). Para o estudo da maçã, as informações foram disponibilizadas pela ABPM, AGAPOMI e pelo Instituto FNP, que publica o Relatório Agrianual.

A coleta de dados, também foi realizada junto a produtores do município de Vacaria e, isto, ocorreu para as três culturas. Esses dados foram analisados, e de forma quantitativa agrupados para realizar os cálculos a fim de se obter a resposta do problema enunciado anteriormente.

Optou-se por adquirir os dados e as informações com as entidades, porém adaptá-las à realidade do município de Vacaria, através de entrevistas e conversas com os produtores rurais, ou seja, tentando chegar o mais perto possível dos dados e informações reais. Os produtores, com sua experiência, conseguem transmitir com clareza o que realmente uma lavoura de alho, de soja e um pomar de maçã têm de custos, despesas e receitas, além de identificar quais são os investimentos iniciais necessários para o produtor que precisa tomar decisão de qual cultura investir.

\section{ESTUDO DE CASO}

Parte-se agora para a efetivação do estudo de caso, onde foram identificados os custos, as despesas e as receitas que compõem a implantação e o desenvolvimento das três culturas, em estudo, ou seja: o alho, a soja e a maçã. 
VICENZI, R.K.F. et al. Rentabilidade e lucratividade das culturas temporárias e permanentes.

PUBVET, Londrina, V. 6, N. 9, Ed. 196, Art. 1313, 2012.

Após a identificação dessas variáveis foram realizados cálculos que serviram de base para mensuração da rentabilidade e da lucratividade das culturas em questão. Ressalta-se, aqui, que duas das culturas em estudo são temporárias, ou seja, anuais, e uma, que é o caso da maçã é permanente.

\subsection{CULTURA TEMPORÁRIA - ALHO}

Os custos e despesas do processo produtivo de um hectare do alho, pode ser verificado na Tabela 1.

Tabela 1: Custos e despesas relacionados à cultura do alho

\begin{tabular}{|c|c|c|c|c|c|c|c|c|c|}
\hline \multirow{2}{*}{ Discriminação } & \multirow{2}{*}{$\begin{array}{l}\text { Unid de } \\
\text { medida }\end{array}$} & \multicolumn{6}{|c|}{ CUSTO POR PERIODO } & \multicolumn{2}{|c|}{ PROJEÇÁO } \\
\hline & & 2007 & $\%$ & 2008 & $\%$ & 2009 & $\%$ & 2010 & $\%$ \\
\hline CUSTOS & & $21.810,00$ & $81 \%$ & $22.230,00$ & $82 \%$ & $22.910,00$ & $82 \%$ & $23.740,00$ & $81 \%$ \\
\hline Insumos & $\mathrm{R} \$ /$ há & $10.670,00$ & $40 \%$ & $10.880,00$ & $40 \%$ & $11.100,00$ & $40 \%$ & $11.400,00$ & $39 \%$ \\
\hline Mão-de-Obra & $\mathrm{R} \$ /$ há & $5.650,00$ & $21 \%$ & $5.770,00$ & $21 \%$ & $6.100,00$ & $22 \%$ & $6.520,00$ & $22 \%$ \\
\hline Serviços de manutenção & $\mathrm{R} \$ /$ há & $3.010,00$ & $11 \%$ & $3.100,00$ & $11 \%$ & $3.200,00$ & $11 \%$ & $3.300,00$ & $11 \%$ \\
\hline Despesas Operacionais & $\mathrm{R} \$ /$ há & 200,00 & $1 \%$ & 200,00 & $1 \%$ & 210,00 & $1 \%$ & 220,00 & $1 \%$ \\
\hline Assitência Técnica & $\mathrm{R} \$ /$ há & 230,00 & $1 \%$ & 230,00 & $1 \%$ & 250,00 & $1 \%$ & 250,00 & $1 \%$ \\
\hline Seguro de produção & $\mathrm{R} \$ /$ há & 370,00 & $1 \%$ & 370,00 & $1 \%$ & 370,00 & $1 \%$ & 370,00 & $1 \%$ \\
\hline Manutenção de benfeitorias & $\mathrm{R} \$ /$ há & 55,00 & $0 \%$ & 55,00 & $0 \%$ & 55,00 & $0 \%$ & 55,00 & $0 \%$ \\
\hline Depreciação de Benfeitorias & $\mathrm{R} \$ /$ há & 375,00 & $1 \%$ & 375,00 & $1 \%$ & 375,00 & $1 \%$ & 375,00 & $1 \%$ \\
\hline Depreciação dos bens móveis & $\mathrm{R} \$ /$ há & $1.250,00$ & $5 \%$ & $1.250,00$ & $5 \%$ & $1.250,00$ & $4 \%$ & $1.250,00$ & $4 \%$ \\
\hline DESPESAS & & $5.050,00$ & $19 \%$ & $4.810,00$ & $18 \%$ & $4.980,00$ & $18 \%$ & $5.670,00$ & $19 \%$ \\
\hline Despesas com comercialização & $\mathrm{R} \$ /$ há & 680,00 & $3 \%$ & 700,00 & $3 \%$ & 720,00 & $3 \%$ & 750,00 & $3 \%$ \\
\hline INSS s/ Produção Rural & $\mathrm{R} \$ /$ há & 690,00 & $3 \%$ & 710,00 & $3 \%$ & 730,00 & $3 \%$ & 680,00 & $2 \%$ \\
\hline ICMS & $\mathrm{R} \$ /$ há & $1.800,00$ & $7 \%$ & $1.860,00$ & $7 \%$ & $1.900,00$ & $7 \%$ & $1.750,00$ & $6 \%$ \\
\hline Mão-de-Obra fix & $\mathrm{R} \$ /$ há & $1.750,00$ & $7 \%$ & $2.100,00$ & $8 \%$ & $2.200,00$ & $8 \%$ & $2.330,00$ & $8 \%$ \\
\hline Despesas Administrativas & $\mathrm{R} \$ /$ há & 130,00 & $0 \%$ & 140,00 & $1 \%$ & 150,00 & $1 \%$ & 160,00 & $1 \%$ \\
\hline TOTAL & $\mathbf{R}$ /há & $26.860,00$ & $100 \%$ & $27.040,00$ & $100 \%$ & $27.890,00$ & $100 \%$ & $29.410,00$ & $100 \%$ \\
\hline
\end{tabular}

Fonte: Produtores da região de Vacaria (RS)

Na Tabela 1 é demonstrado um resumo dos custos e despesas que nortearam três safras anteriores, ou seja, 2007, 2008 e 2009 e uma projeção para a safra de 2010, com base em dados e informações de produtores e algumas adaptadas, como é o caso da depreciação, por exemplo.

É importante frisar, que os valores apresentados na Tabela 1, são equivalentes ao cultivo de um hectare, e como o objetivo é apresentar os custos relativos a 120 hectares, é preciso que o valor total seja multiplicado 
VICENZI, R.K.F. et al. Rentabilidade e lucratividade das culturas temporárias e permanentes. PUBVET, Londrina, V. 6, N. 9, Ed. 196, Art. 1313, 2012.

por este número de hectares e, assim, se obtêm o total de custos e despesas para a totalidade da área.

Os insumos, que conforme pode ser visualizado representa em média $40 \%$ do total. Neste caso, compõem esse item as sementes, o calcário e o adubo de base e corretivo, adubo orgânico, os defensivos utilizados para o tratamento da semente, além de herbicidas, fungicidas e inseticidas recomendados para o bom desenvolvimento da cultura.

No caso da mão-de-obra que é o outro item mais representativo na composição apresentado na Tabela 1, está inserida a utilização desta para a aplicação do calcário, adubos e defensivos, para a limpeza dos caminhos através da capina, para a irrigação, para o plantio, que conforme visto é realizado, quase que totalmente, manualmente. Além disso, classificam-se, o serviço de colheita, de armazenagem, da classificação, limpeza e embalagem do produto.

Foram alocados, também, na Tabela 1, os serviços de manutenção das máquinas e implementos agrícolas, a assistência técnica, os custos provenientes da manutenção das benfeitorias, que se resumem nos galpões utilizados para a cura do alho. Já nas despesas, foram demonstrados os gastos que o produtor terá com a administração da propriedade e com a comercialização do produto, que engloba embalagens e frete. Compõe, também, as despesas, o INSS sobre a Produção Rural e o ICMS. O INSS sobre a Produção Rural resulta da aplicação da alíquota de 2,3\% sobre o total da receita bruta obtida e o ICMS, da aplicação da alíquota específica.

Ressalta-se que para o cálculo do INSS da Produção Rural e do ICMS, se procurou primeiro calcular a receita bruta de comercialização. Para evidenciar a receita identificou-se primeiro o preço médio recebido pela venda do produto, conforme demonstrado na Tabela 2. 
VICENZI, R.K.F. et al. Rentabilidade e lucratividade das culturas temporárias e permanentes.

PUBVET, Londrina, V. 6, N. 9, Ed. 196, Art. 1313, 2012.

Tabela 2: Preço médio recebido

\begin{tabular}{c|c|c|c|c}
\hline & 2007 & 2008 & 2009 & $2010\left(^{*}\right)$ \\
\hline Preço Médio Recebido & $\mathrm{R} \$ 4,66$ & $\mathrm{R} \$ 4,79$ & $\mathrm{R} \$ 4,93$ & $\mathrm{R} \$ 4,67$ \\
\hline
\end{tabular}

Fonte: Preço médio dos produtores da região de Vacaria (RS)

(*) Estimativa do preço de venda para $2010^{1}$

Na Tabela 2, pode ser visualizado o preço médio recebido pela venda de alho nos anos de 2007, 2008 e 2009 e a previsão segundo Lucini (2010) do preço que irá ser pago na próxima safra. Neste caso, os produtores consultados alertam que esses preços podem ter variações, dependendo do mercado consumidor.

De posse dos preços médios praticados, considerou-se a produtividade média do estado do Rio Grande do Sul, que é de 7.000 quilos/ha, perfazendo um total de colheita equivalente a 840.000 quilos. Com este total, calculou-se a receita que o produtor obteria com a venda do seu produto, multiplicando o preço médio recebido, apresentado na Tabela 2, pela produtividade total estimada. Essa receita está demonstrada Tabela 3.

Tabela 3: Receita da venda do produto

\begin{tabular}{l|c|c|c|c}
\hline & 2007 & 2008 & 2009 & 2010 \\
\hline Receita & $3.914 .400,00$ & $4.023 .600,00$ & $4.141 .200,00$ & $3.922 .800,00$ \\
\hline
\end{tabular}

Foram calculados os impostos, ou seja, o INSS sobre a Produção Rural e o ICMS. No caso do ICMS, utilizou-se a alíquota de $12 \%$, já que os maiores consumidores de alho no Brasil encontram-se nos estados de São Paulo e Rio de Janeiro.

Do valor apurado de ICMS, calculou-se $50 \%$ de crédito presumido conforme prevê o Regulamento do ICMS do estado do Rio Grande do Sul. O

\footnotetext{
${ }^{1}$ LUCINI, Marco Antônio. Alho - Preços Médios Recebidos de 1999 a 2010. ANAPA, Associação Nacional de Produtores do Alho. Disponível em: <http://www.anapa.com.br/principal/images/stories/importacoes/recebidos.pdf > Acesso em: 20 ago 2010
} 
VICENZI, R.K.F. et al. Rentabilidade e lucratividade das culturas temporárias e permanentes. PUBVET, Londrina, V. 6, N. 9, Ed. 196, Art. 1313, 2012.

resultado destes cálculos é evidenciado na Tabela 1, porém há de se lembrar que o valor apresentado na referida Tabela, contempla apenas um hectare.

Com os valores dos custos, das despesas e das receitas, já apurados, foi elaborada uma Demonstração do Resultado do Exercício (DRE), com o objetivo de evidenciar qual seria o lucro gerado na produção de alho. Na Tabela 4, portanto, pode ser visualizada a DRE referente às safras de 2007, 2008 e 2009, além da previsão para a safra de 2010:

Tabela 4: Demonstração do Resultado do Exercício - cultura do alho

\begin{tabular}{l|r|r|r|r}
\hline & \multicolumn{1}{|c|}{$\mathbf{2 0 0 7}$} & \multicolumn{1}{c|}{$\mathbf{2 0 0 8}$} & \multicolumn{1}{c}{$\mathbf{2 0 0 9}$} & \multicolumn{1}{c}{$\mathbf{2 0 1 0}$} \\
\hline RECEITA BRUTA & $\mathbf{3 . 9 1 4 . 4 0 0 , 0 0}$ & $\mathbf{4 . 0 2 3 . 6 0 0 , 0 0}$ & $\mathbf{4 . 1 4 1 . 2 0 0 , 0 0}$ & $\mathbf{3 . 9 2 2 . 8 0 0 , 0 0}$ \\
$\begin{array}{l}\text { (-) Deduções Receita Bruta } \\
\text { (INSS e ICMS) }\end{array}$ & $(324.895,20)$ & $(333.958,80)$ & $(343.719,60)$ & $(325.592,40)$ \\
RECEITA LíQUIDA & $3.589 .504,80$ & $3.689 .641,20$ & $3.797 .480,40$ & $3.597 .207,60$ \\
(-) Custo Produto Vendido & $(2.617 .200,00)$ & $(2.667 .600,00)$ & $(2.749 .200,00)$ & $(2.848 .800,00)$ \\
LUCRO BRUTO & $\mathbf{9 7 2 . 3 0 4 , 8 0}$ & $\mathbf{1 . 0 2 2 . 0 4 1 , 2 0}$ & $\mathbf{1 . 0 4 8 . 2 8 0 , 4 0}$ & $\mathbf{7 4 8 . 4 0 7 , 6 0}$ \\
(-) Despesas Oper/Administ & $(606.000,00)$ & $(577.200,00)$ & $(597.600,00)$ & $(680.400,00)$ \\
\hline LUCRO BRUTO & $\mathbf{3 6 6 . 3 0 4 , 8 0}$ & $\mathbf{4 4 4 . 8 4 1 , 2 0}$ & $\mathbf{4 5 0 . 6 8 0 , 4 0}$ & $\mathbf{6 8 . 0 0 7 , 6 0}$ \\
\hline
\end{tabular}

Na Tabela 4, é demonstrada uma DRE das safras 2007 a 2010. Pode ser observado, diante disso, que a cultura proporciona lucro em todas as safras apresentadas. O lucro está estável em $11 \%$ nas três primeiras safras, porém, a safra de 2010 apresenta um lucro inferior, que pode ser justificado pelo preço estar estimado abaixo do que vem ocorrendo e os custos tiveram uma projeção de alta.

Deve-se salientar, porém, que este resultado não é uniforme e que há inúmeras variáveis que não foram consideradas neste trabalho. Não são contabilizadas, por exemplo, alguma perda de safra em virtude de fatores climáticos ou elevação da importação do produto. 
VICENZI, R.K.F. et al. Rentabilidade e lucratividade das culturas temporárias e permanentes.

PUBVET, Londrina, V. 6, N. 9, Ed. 196, Art. 1313, 2012.

Todas essas informações referentes ao cultivo do alho, investimento custos, receitas, despesas e lucro, pode-se seguir com a análise da rentabilidade e da lucratividade com a aplicação do VPL, da TIR e do EBITDA, conforme evidenciado no item a seguir.

\subsubsection{Rentabilidade e lucratividade}

Para se calcular o VPL e a TIR, foi elaborado, uma planilha eletrônica Excel, um fluxo de caixa líquido, de acordo com Kassai et. al (2000), os quais estão apresentados na Figura 1.

\begin{tabular}{|c|c|c|c|c|c|c|}
\hline & A & B & C & D & $E$ & $\mathbf{F}$ \\
\hline 1 & Safra & Inves time nto & Receitas & Custos & Despesas & $\begin{array}{c}\text { Fluxo de Caixa } \\
\text { Líquido }\end{array}$ \\
\hline 2 & 0 & $(824.879,00)$ & & & & $(824.879,00)$ \\
\hline 3 & 2007 & & $3.914 .400,00$ & $(2.617 .200,00)$ & $(930.895,20)$ & $366.304,80$ \\
\hline 4 & 2008 & & 4.023.600,00 & $(2.667 .600,00)$ & $(911.158,80)$ & $444.841,20$ \\
\hline 5 & 2009 & & $4.141 .200,00$ & $(2.749 .200,00)$ & $(941.319,60)$ & $450.680,40$ \\
\hline 6 & 2010 & & $3.922 .800,00$ & $(2.848 .800,00)$ & $(1.005 .992,40)$ & $68.007,60$ \\
\hline 7 & \multicolumn{5}{|c|}{ Taxa mínima de atratividade considerada: } & $10 \%$ \\
\hline 8 & & & & & & \\
\hline 9 & & & & $(\mathrm{~F} 7 ; \mathrm{F3}: \mathrm{F6})+\mathrm{B} 2$ & & TIR(F2:F6;F7) \\
\hline 10 & & & VPL $=$ & $260.815,68$ & TIR = & $26 \%$ \\
\hline
\end{tabular}

Figura 1: Fluxo de caixa líquido, valor do VPL e da TIR

Observa-se na Figura 1, o fluxo de caixa líquido, onde se apresenta o valor de $\mathrm{R} \$ 824.879,00$, gasto com o investimento inicial em máquinas e equipamentos agrícolas, veículos, sistema de irrigação, galpões para cura do alho e máquina de classificar, além dos custos, as despesas e as receitas e, por fim, o lucro líquido encontrado, o mesmo que consta na DRE (Tabela 4).

O VPL, conforme já mencionado, é obtido, segundo Assaf Neto (2003), pela diferença entre o valor presente dos benefícios líquidos de caixa, previstos para cada período do horizonte de duração do projeto, e o valor presente do 
VICENZI, R.K.F. et al. Rentabilidade e lucratividade das culturas temporárias e permanentes. PUBVET, Londrina, V. 6, N. 9, Ed. 196, Art. 1313, 2012.

investimento, que é o desembolso de caixa inicial. O VPL deve ser calculado levando em consideração uma determinada TMA (KASSAI, et. al. 2000), estabelecida em $10 \%$ (dez por cento), que seria o mínimo de retorno que a cultura poderia oferecer, em comparação com a taxa da poupança, que é uma das menores existentes.

Através do Fluxo de Caixa Líquido calculou-se o VPL e a TIR que podem ser analisados através da Figura 1, estes também em concordância com Kassai et. al. (2000). Diante da Figura 1 constata-se que o VPL resultou em $R \$$ $260.815,68$, o que segundo os autores é satisfatório, porque o investimento é considerado atraente para o produtor, ou seja, o resultado do VPL foi superior a zero, quando considerada uma taxa mínima de $10 \%$.

Com base na mesma planilha eletrônica de Excel e demonstrada na Figura 1, calculou-se a TIR, que segundo Assaf Neto (2003) representa a taxa de desconto que iguala, em determinado momento as entradas com as saídas de caixa, ou seja, quando zera o VPL.

De acordo com o demonstrado na Figura 1, a TIR resultou em 26\%. Assaf Neto (2003) lembra que a aceitação ou rejeição de um determinado projeto de investimento é decidida em função do processo de comparação entre a TIR e a TMA. Anteriormente, foi estabelecida uma TMA de $10 \%$ e a TIR se apresentou $26 \%$, o que demonstra que haverá um retorno superior ao almejado.

Para calcular o Ebitda toma-se como base a DRE demonstrada na Tabela 4 e elabora-se uma outra DRE, transferindo os gastos com depreciação para depois do Lucro Operacional Ajustado, contemplado pelo Ebitda. Na Tabela 5, essa transferência pode ser verificada: 
VICENZI, R.K.F. et al. Rentabilidade e lucratividade das culturas temporárias e permanentes.

PUBVET, Londrina, V. 6, N. 9, Ed. 196, Art. 1313, 2012.

Tabela 5: Demonstração do Resultado do Exercício - Ebitda da cultura do Alho

\begin{tabular}{l|r|r|r|r}
\hline & \multicolumn{1}{|c|}{$\mathbf{2 0 0 7}$} & \multicolumn{1}{c|}{$\mathbf{2 0 0 8}$} & \multicolumn{1}{c}{$\mathbf{2 0 0 9}$} & \multicolumn{1}{c}{$\mathbf{2 0 1 0}$} \\
\hline RECETTA BRUTA & $\mathbf{3 . 9 1 4 . 4 0 0 , 0 0}$ & $\mathbf{4 . 0 2 3 . 6 0 0 , 0 0}$ & $\mathbf{4 . 1 4 1 . 2 0 0 , 0 0}$ & $\mathbf{3 . 9 2 2 . 8 0 0 , 0 0}$ \\
(-) Deduções Receita Bruta & $(324.895,20)$ & $(333.958,80)$ & $(343.719,60)$ & $(325.592,40)$ \\
(INSS e ICMS) & $3.589 .504,80$ & $3.689 .641,20$ & $3.797 .480,40$ & $3.597 .207,60$ \\
RECEITA LÍQUIDA & $(2.422 .200,00)$ & $(2.472 .600,00)$ & $(2.554 .200,00)$ & $(2.653 .800,00)$ \\
(-) Custo Produto Vendido & $\mathbf{1 . 1 6 7 . 3 0 4 , 8 0}$ & $\mathbf{1 . 2 1 7 . 0 4 1 , 2 0}$ & $\mathbf{1 . 2 4 3 . 2 8 0 , 4 0}$ & $\mathbf{9 4 3 . 4 0 7 , 6 0}$ \\
LUCRO BRUTO & $(606.000,00)$ & $(577.200,00)$ & $(597.600,00)$ & $(680.400,00)$ \\
(-) Despesas Oper/Administ & $\mathbf{5 6 1 . 3 0 4 , 8 0}$ & $\mathbf{6 3 9 . 8 4 1 , 2 0}$ & $\mathbf{6 4 5 . 6 8 0 , 4 0}$ & $\mathbf{2 6 3 . 0 0 7 , 6 0}$ \\
EBITDA/LUCRO OP. AJUSTADO & $(195.000,00)$ & $(195.000,00)$ & $(195.000,00)$ & $(195.000,00)$ \\
(-) Despesas escriturais & $\mathbf{3 6 6 . 3 0 4 , 8 0}$ & $\mathbf{4 4 4 . 8 4 1 , 2 0}$ & $\mathbf{4 5 0 . 6 8 0 , 4 0}$ & $\mathbf{6 8 . 0 0 7 , 6 0}$ \\
\hline LUCRO BRUTO & &
\end{tabular}

Percebe-se, através da Tabela 5, que o Lucro Operacional Ajustado é resultante da receita de vendas diminuindo os custos e as despesas, porém nestes custos não está incluída a depreciação, pois segundo Vasconcelos (2002) esse item não representa saída de recursos financeiros. Neste caso a lucratividade aumenta conforme está demonstrado na Tabela 6, onde são comparados os dois lucros apurados:

Tabela 6: Comparativo entre os resultados das DREs - cultura do alho

\begin{tabular}{l|r|r|r|r}
\hline & \multicolumn{1}{|c|}{$\mathbf{2 0 0 7}$} & \multicolumn{1}{c|}{$\mathbf{2 0 0 8}$} & \multicolumn{1}{c}{$\mathbf{2 0 0 9}$} & \multicolumn{1}{c}{$\mathbf{2 0 1 0}$} \\
\hline Receita Líquida & $3.589 .504,80$ & $3.689 .641,20$ & $3.797 .480,40$ & $3.597 .207,60$ \\
Lucro líquido & $366.304,80$ & $444.841,20$ & $450.680,40$ & $68.007,60$ \\
Lucratividade & $10 \%$ & $12 \%$ & $12 \%$ & $2 \%$ \\
Lucro Ebitda & $561.304,80$ & $639.841,20$ & $645.680,40$ & $263.007,60$ \\
Lucratividade Ebitda & $16 \%$ & $17 \%$ & $17 \%$ & $7 \%$ \\
Variação da Lucratividade & $5 \%$ & $5 \%$ & $5 \%$ & $5 \%$ \\
\hline
\end{tabular}

Na Tabela 6, são comparados os resultados da DRE da Tabela 4 com os da DRE da Tabela 5, neste último caso, onde é calculado o Ebitda. É 
VICENZI, R.K.F. et al. Rentabilidade e lucratividade das culturas temporárias e permanentes. PUBVET, Londrina, V. 6, N. 9, Ed. 196, Art. 1313, 2012.

perceptível, portanto, ao se analisar a Tabela 6, que o Ebitda aumenta em cinco pontos percentuais a lucratividade do produtor o que demonstra que ele tem um bom desempenho financeiro já que o cálculo do Ebitda não contempla a depreciação, que não representa saída de caixa efetiva.

Seguindo o que consta na Tabela 6 , pode-se dizer que a cultura do alho tem potencial para gerar recursos e que, a safra de 2010 mesmo sendo uma estimativa, na apresentação de seu lucro líquido na DRE, este se apresentava em $2 \%$. Por outro lado, ao se efetuar o cálculo do Ebitda esse percentual chega a $7 \%$ de lucratividade.

Da mesma forma que foi realizada uma abordagem sobre a cultura do alho, evidenciando os investimentos necessários, os custos, as despesas e as receitas e, essas informações servindo de base para os cálculos do VPL, da TIR e do Ebitda, a seguir será tratado sobre a cultura da soja.

\subsection{CULTURA TEMPORÁRIA - SOJA}

Da mesma forma, que foram apresentados os itens que fazem parte da cultura do alho, serão mencionados os investimentos que seriam necessários para plantar 120 hectares de soja, sendo que esses foram resultado, também, de questionamentos realizados aos produtores de soja do município. Os produtores informaram que as máquinas a serem utilizadas no plantio e na colheita são alugadas.

Apresenta-se, agora, com base em dados fornecidos pela EPAGRI/CEPA (2006/2007) e informações adquiridas no Relatório Agrianual (2006) e com produtores da região os custos e despesas que envolvem o plantio de um hectare de soja, apresentados na Tabela 7: 
VICENZI, R.K.F. et al. Rentabilidade e lucratividade das culturas temporárias e permanentes.

PUBVET, Londrina, V. 6, N. 9, Ed. 196, Art. 1313, 2012.

Tabela 7: Custos e despesas relacionados à cultura da soja

\begin{tabular}{|c|c|c|c|c|c|c|c|c|c|}
\hline \multirow{2}{*}{ Discriminação } & \multirow{2}{*}{$\begin{array}{l}\text { Unid de } \\
\text { Medida }\end{array}$} & \multicolumn{6}{|c|}{ CUSTO POR PERÍODO } & \multicolumn{2}{|c|}{ PROJEÇÃO } \\
\hline & & 2007 & $\%$ & 2008 & $\%$ & 2009 & $\%$ & 2010 & $\%$ \\
\hline CUSTOS & & $1.418,00$ & $90 \%$ & $1.411,00$ & $90 \%$ & $1.461,00$ & $90 \%$ & $1.541,00$ & $90 \%$ \\
\hline Insumos & R\$/há & 557,00 & $35 \%$ & 562,00 & $36 \%$ & 590,00 & $36 \%$ & 627,00 & $37 \%$ \\
\hline Mão-de-Obra & $\mathrm{R} \$$ /há & 28,00 & $2 \%$ & 28,00 & $2 \%$ & 29,00 & $2 \%$ & 31,00 & $2 \%$ \\
\hline Serviços mecânicos/aluguel/máquinas & $\mathrm{R} \$ / h a ́$ & 432,00 & $27 \%$ & 436,00 & $28 \%$ & 458,00 & $28 \%$ & 487,00 & $28 \%$ \\
\hline Assistência técnica & R\$/há & 21,00 & $1 \%$ & 21,00 & $1 \%$ & 22,00 & $1 \%$ & 24,00 & $1 \%$ \\
\hline Manutenção de benfeitorias/máquinas & R\$/há & 43,00 & $3 \%$ & 45,00 & $3 \%$ & 47,00 & $3 \%$ & 50,00 & $3 \%$ \\
\hline Frete(até o silo e/ou Cooperativa) & $\mathrm{R} \$$ há & 16,00 & $1 \%$ & 16,00 & $1 \%$ & 16,00 & $1 \%$ & 16,00 & $1 \%$ \\
\hline Secag/limpeza/armazenag/Cooperativa & $\mathrm{R} \$$ /há & 69,00 & $4 \%$ & 51,00 & $3 \%$ & 47,00 & $3 \%$ & 54,00 & $3 \%$ \\
\hline Depreciação dos bens móveis & $\mathrm{R} \$$ há & 252,00 & $16 \%$ & 252,00 & $16 \%$ & 252,00 & $16 \%$ & 252,00 & $15 \%$ \\
\hline DESPESAS & & 162,00 & $10 \%$ & 154,00 & $10 \%$ & 156,00 & $10 \%$ & 169,00 & $10 \%$ \\
\hline Despesas Operacionais & $\mathrm{R}$ \$há & 22,00 & $1 \%$ & 23,00 & $1 \%$ & 24,00 & $1 \%$ & 25,00 & $1 \%$ \\
\hline INSS s/ Produção Rural & $\mathrm{R}$ \$há & 53,00 & $3 \%$ & 39,00 & $2 \%$ & 36,00 & $2 \%$ & 42,00 & $2 \%$ \\
\hline Mão-de-obra fixa & R\$há & 87,00 & $6 \%$ & 92,00 & $6 \%$ & 96,00 & $6 \%$ & 102,00 & $6 \%$ \\
\hline TOTAL & R\$/há & $1.580,00$ & $100 \%$ & $1.565,00$ & $100 \%$ & $1.617,00$ & $100 \%$ & $1.710,00$ & $100 \%$ \\
\hline
\end{tabular}

Fonte: EPAGRI/CEPA/Relatório Agrianual (2006)/Produtores

São apresentados na Tabela 7, os custos e despesas que o produtor terá para o plantio de um hectare de soja, sendo que, como foi realizado na cultura do alho, haverá uma explicação para cada item. Do total dos custos e despesas, os insumos representam em média $37 \%$, outro item que chama a atenção é os serviços mecânicos e aluguel de máquinas. Caso o produtor ainda não tenha o maquinário suficiente para a realização total das atividades, necessita que as máquinas sejam alugadas, esse processo contribui com $28 \%$ dos custos. Por ser uma cultura extremamente mecanizada, a soja não utiliza mão de obra temporária. O item considerado despesa representa $10 \%$.

Explicada a composição dos custos e das despesas relativos à cultura da soja, a Tabela 8 , apresenta a média de preços do produto por saco de 60 quilos praticado pelos produtores pesquisados no município de Vacaria. É relevante destacar que os preços de venda do saco de soja são extremamente flutuantes, sua cotação é diária baseada na bolsa de Chicago (US), e complementarmente o período em que este produto é vendido é também uma variável subjetiva que deve ser considerada na análise de projetos de investimento. 
VICENZI, R.K.F. et al. Rentabilidade e lucratividade das culturas temporárias e permanentes.

PUBVET, Londrina, V. 6, N. 9, Ed. 196, Art. 1313, 2012.

Tabela 8: Preço médio - saco de $60 \mathrm{~kg}$ - soja

\begin{tabular}{l|c|c|c|c}
\hline & 2007 & 2008 & 2009 & $2010\left(^{*}\right)$ \\
\hline $\begin{array}{l}\text { Preço Médio Recebido/sc } \\
60 \mathrm{Kg}\end{array}$ & $\mathrm{R} \$ 38,00$ & $\mathrm{R} \$ 36,00$ & $\mathrm{R} \$ 46,00$ & $\mathrm{R} \$ 45,00$ \\
\hline
\end{tabular}

Fonte: Média do preço recebido pelos produtores

Nota-se na Tabela 8 que os preços do produto variam e que a safra de 2009 está entre as melhores na opinião dos produtores. Essa variação é justificável, pois a comercialização do produto depende de inúmeros fatores, inclusive se a safra foi positiva ou não.

Tendo ciência da média de preço que o produto teve de 2007 a 2009 e projetando-se o preço para 2010, multiplicado pela produtividade estimada pela EPAGRI/CEPA (2006/2007), de 55 sacos/ha, se tem possibilidade de elaborar uma DRE que demonstrará qual seria o lucro do produtor. Na Tabela 9, então é colocada á apreciação uma DRE da soja.

Tabela 9: Demonstração do Resultado do Exercício - cultura da soja

\begin{tabular}{l|r|r|r|r}
\hline & \multicolumn{1}{|c|}{$\mathbf{2 0 0 7}$} & \multicolumn{1}{c|}{$\mathbf{2 0 0 8}$} & \multicolumn{1}{c|}{$\mathbf{2 0 0 9}$} & \multicolumn{1}{c}{$\mathbf{2 0 1 0}$} \\
\hline RECEITA BRUTA & $\mathbf{2 5 0 . 8 0 0 , 0 0}$ & $\mathbf{2 3 7 . 6 0 0 , 0 0}$ & $\mathbf{2 9 7 . 0 0 0 , 0 0}$ & $\mathbf{2 9 0 . 4 0 0 , 0 0}$ \\
(-) Deduções Receita Bruta & $(5.768,40)$ & $(5.464,80)$ & $(6.831,00)$ & $(6.679,20)$ \\
(INSS) & $245.031,60$ & $232.135,20$ & $290.169,00$ & $283.720,80$ \\
RECEITA LÍQUIDA & $(170.160,00)$ & $(169.320,00)$ & $(175.320,00)$ & $(184.920,00)$ \\
(-) Custo Produto Vendido & $\mathbf{7 4 . 8 7 1 , 6 0}$ & $\mathbf{6 2 . 8 1 5 , 2 0}$ & $\mathbf{1 1 4 . 8 4 9 , 0 0}$ & $\mathbf{9 8 . 8 0 0 , 8 0}$ \\
LUCRO BRUTO & $(19.440,00)$ & $(18.480,00)$ & $(18.720,00)$ & $(20.280,00)$ \\
(-) Despes as Oper/Administ & $\mathbf{5 5 . 4 3 1 , 6 0}$ & $\mathbf{4 4 . 3 3 5 , 2 0}$ & $\mathbf{9 6 . 1 2 9 , 0 0}$ & $\mathbf{7 8 . 5 2 0 , 8 0}$ \\
\hline LUCRO BRUTO & & &
\end{tabular}

Os produtores consultados, colocam que o preço da soja sofre inúmeras influências, dentre elas, podem ser citadas a valorização do real perante o dólar, a safra norte-americana, estiagens, entre outras e que a produtividade estimada, por exemplo, está em 55 sacos/ha, o que é considerada excelente para os produtores. 
VICENZI, R.K.F. et al. Rentabilidade e lucratividade das culturas temporárias e permanentes.

PUBVET, Londrina, V. 6, N. 9, Ed. 196, Art. 1313, 2012.

\subsubsection{Rentabilidade e lucratividade}

Com base nas informações obtidas da DRE foi elaborado um Fluxo de Caixa Líquido, da mesma forma que foram conduzidos os cálculos da cultura do alho. E, de posse do Fluxo de Caixa calculou-se o VPL e a TIR, conforme demonstrado na Figura 2:

\begin{tabular}{|c|c|c|c|c|c|c|}
\hline & $\bar{A}$ & B & C & D & $E$ & $\mathbf{F}$ \\
\hline 1 & Safra & Investimento & Receitas & Custos & Despesas & $\begin{array}{c}\text { Fluxo de Caixa } \\
\text { Líquido } \\
\end{array}$ \\
\hline 2 & 0 & $(121.000,00)$ & & & & $(121.000,00)$ \\
\hline 3 & 2007 & & $250.800,00$ & $(170.160,00)$ & $(25.208,40)$ & $55.431,60$ \\
\hline 4 & 2008 & & $237.600,00$ & $(169.320,00)$ & $(23.944,80)$ & $44.335,20$ \\
\hline 5 & 2009 & & $297.000,00$ & $(175.320,00)$ & $(25.551,00)$ & $96.129,00$ \\
\hline 6 & 2010 & & $290.400,00$ & $(184.920,00)$ & $(26.959,20)$ & $78.520,80$ \\
\hline 7 & \multicolumn{5}{|c|}{ Taxa mínima de atratividade considerada: } & $10 \%$ \\
\hline 8 & & & & & & \\
\hline 9 & & & \multicolumn{2}{|c|}{$=\mathrm{VPL}(\mathrm{F} 7 ; \mathrm{F} 3: \mathrm{F} 6)+\mathrm{B} 2$} & \multicolumn{2}{|c|}{$=\mathrm{TIR}(\mathrm{F} 2: \mathrm{F} 6 ; \mathrm{F} 7)$} \\
\hline 10 & & & VPL $=$ & $91.886,93$ & TIR $=$ & $38 \%$ \\
\hline
\end{tabular}

Figura 2: Fluxo de Caixa Líquido - Cálculo do VPL e da TIR

Observa-se na Figura 2, o fluxo de caixa líquido, e o valor dos $\mathrm{R} \$$ 121.000,00 aplicados na aquisição de um veículo, um trator e um pulverizador como investimento inicial, além dos custos, as despesas e as receitas e, por fim, o lucro líquido encontrado, o mesmo que consta na DRE (Tabela 9).

Ainda em relação aos investimentos iniciais, o número de máquinas e implementos agrícolas restringem-se a dois itens, pois conforme dito anteriormente os equipamentos que servirão para o plantio e para a colheita são, na maioria das vezes, alugados. Os produtores que já trabalham com o cultivo de lavouras, há algum tempo, conseguem ampliar o seu imobilizado com aquisições de máquinas colhedoras e plantadoras, mas geralmente, são contratados financiamentos.

Conforme pode ser observado na Figura 2, o VPL teve um resultado positivo, portanto, o investimento é atraente (KASSAI et. al., 2000). 
VICENZI, R.K.F. et al. Rentabilidade e lucratividade das culturas temporárias e permanentes. PUBVET, Londrina, V. 6, N. 9, Ed. 196, Art. 1313, 2012.

De igual forma, com base no Fluxo de Caixa Líquido, calculou-se a TIR, demonstrada na Figura 2, obtendo-se o resultado de 38\%.

Tem-se, de acordo com a Figura 2, como resultados atrativos ao produtor, e refletem uma boa performance dos preços de venda e da produtividade alcançada para o período analisado.

Continuando com o estudo da rentabilidade e da lucratividade da cultura da soja, consta na Tabela 10, uma DRE simplificada que contempla o Ebitda:

Tabela 10: Demonstração do Resultado do Exercício - Ebitda da soja

\begin{tabular}{l|r|r|r|r}
\hline & \multicolumn{1}{|c|}{$\mathbf{2 0 0 7}$} & \multicolumn{1}{c|}{$\mathbf{2 0 0 8}$} & \multicolumn{1}{c}{$\mathbf{2 0 0 9}$} & \multicolumn{1}{c}{$\mathbf{2 0 1 0}$} \\
\hline RECEITA BRUTA & $\mathbf{2 5 0 . 8 0 0 , 0 0}$ & $\mathbf{2 3 7 . 6 0 0 , 0 0}$ & $\mathbf{2 9 7 . 0 0 0 , 0 0}$ & $\mathbf{2 9 0 . 4 0 0 , 0 0}$ \\
(-) Deduções Receita Bruta & $(5.768,40)$ & $(5.464,80)$ & $(6.831,00)$ & $(6.679,20)$ \\
(INSS) & $245.031,60$ & $232.135,20$ & $290.169,00$ & $283.720,80$ \\
RECEITA LÍQUIDA & $(139.920,00)$ & $(139.080,00)$ & $(145.080,00)$ & $(154.680,00)$ \\
(-) Custo Produto Vendido & $\mathbf{1 0 5 . 1 1 1 , 6 0}$ & $\mathbf{9 3 . 0 5 5 , 2 0}$ & $\mathbf{1 4 5 . 0 8 9 , 0 0}$ & $\mathbf{1 2 9 . 0 4 0 , 8 0}$ \\
LUCRO BRUTO & $(19.440,00)$ & $(18.480,00)$ & $(18.720,00)$ & $(20.280,00)$ \\
(-) Despesas Oper/Administ & $\mathbf{8 5 . 6 7 1 , 6 0}$ & $\mathbf{7 4 . 5 7 5 , 2 0}$ & $\mathbf{1 2 6 . 3 6 9 , 0 0}$ & $\mathbf{1 0 8 . 7 6 0 , 8 0}$ \\
EBITDA/LUCRO OP. AJUSTADO & $(30.240,00)$ & $(30.240,00)$ & $(30.240,00)$ & $(30.240,00)$ \\
(-) Despesas escriturais & $\mathbf{5 5 . 4 3 1 , 6 0}$ & $\mathbf{4 4 . 3 3 5 , 2 0}$ & $\mathbf{9 6 . 1 2 9 , 0 0}$ & $\mathbf{7 8 . 5 2 0 , 8 0}$ \\
\hline LUCRO BRUTO & & & &
\end{tabular}

Com a evidenciação da DRE Ebitda, demonstrada na Tabela 10, percebese que a lucratividade da cultura aumenta, pois conforme preceitua os conceitos deste método de análise do lucro, as despesas escriturais, como a depreciação não são computadas para o cálculo do lucro operacional ajustado, já que neste caso, não há desembolso de valores.

A Tabela 11 contempla um comparativo das duas DREs apresentadas para a cultura da soja: 
VICENZI, R.K.F. et al. Rentabilidade e lucratividade das culturas temporárias e permanentes.

PUBVET, Londrina, V. 6, N. 9, Ed. 196, Art. 1313, 2012.

Tabela 11: Comparativo entre os resultados das DREs - Cultura da soja

\begin{tabular}{l|r|r|r|r}
\hline & \multicolumn{1}{|c|}{$\mathbf{2 0 0 7}$} & \multicolumn{1}{c|}{$\mathbf{2 0 0 8}$} & \multicolumn{1}{c}{$\mathbf{2 0 0 9}$} & \multicolumn{1}{c}{$\mathbf{2 0 1 0}$} \\
\hline Receita Líquida & $245.031,60$ & $232.135,20$ & $290.169,00$ & $283.720,80$ \\
Lucro líquido & $55.431,60$ & $44.335,20$ & $96.129,00$ & $78.520,80$ \\
Lucratividade & $23 \%$ & $19 \%$ & $33 \%$ & $28 \%$ \\
Lucro Ebitda & $85.671,60$ & $74.575,20$ & $126.369,00$ & $108.760,80$ \\
Lucratividade Ebitda & $35 \%$ & $32 \%$ & $44 \%$ & $38 \%$ \\
Variação da Lucratividade & $12 \%$ & $13 \%$ & $10 \%$ & $11 \%$ \\
\hline
\end{tabular}

O que chama a atenção quando se visualiza a Tabela 11 é a variação entre a rentabilidade e a lucratividade ser superior a cultura do alho, e ao mesmo tempo percebe-se que está volatilidade positiva é o reflexo da política de preços de venda em conjunto com a boa administração da propriedade. $\mathrm{O}$ produtor de soja, ao analisar, os resultados da safra através do Ebitda notará que tem lucratividade.

\subsection{MAÇÃ}

A maçã diferentemente do alho e da soja transgênica, é uma cultura permanente, ou seja, continuará a existir por mais de um ano, oferece mais de uma colheita com a mesma qualidade. Essa condição de cultura permanente dá à maçã a possibilidade de imobilizar os valores relativos à implantação do pomar, ou seja, enquanto este não der frutos, não produzir.

A Tabela 12 foi elaborada com base em informações do Relatório Agrianual (2006) e da ABPM, demonstrando qual seria o investimento para a implantação de um pomar: 
VICENZI, R.K.F. et al. Rentabilidade e lucratividade das culturas temporárias e permanentes.

PUBVET, Londrina, V. 6, N. 9, Ed. 196, Art. 1313, 2012.

Tabela 12: Gastos financeiros inicias para implantação de um pomar de maçã

\begin{tabular}{|c|c|c|c|c|c|c|}
\hline \multirow{3}{*}{ Descrição } & \multirow{2}{*}{\multicolumn{2}{|c|}{ Fase de Implantação }} & \multicolumn{4}{|c|}{ Fase de Manutenção } \\
\hline & & & \multicolumn{2}{|c|}{ Ano 1} & \multicolumn{2}{|c|}{ Ano 2} \\
\hline & Valor/ha & Valor Total & Valor/ha & Valor Total & Valor/ha & Valor Total \\
\hline A - Cons trução da Espaldeira & $4.495,00$ & $539.400,00$ & & & & \\
\hline A1. Material & $3.157,00$ & $378.840,00$ & & & & \\
\hline A2. Mão de obra & $1.338,00$ & $160.560,00$ & & & & \\
\hline B - Operações Mecanizadas & $2.132,00$ & $255.840,00$ & 816,00 & $97.920,00$ & $1.223,00$ & $146.760,00$ \\
\hline B1.Preparo do solo & $1.790,00$ & $214.800,00$ & 0,00 & 0,00 & 0,00 & 0,00 \\
\hline B2.Tratos culturais & 342,00 & $41.040,00$ & 816,00 & $97.920,00$ & $1.223,00$ & $146.760,00$ \\
\hline C - Operações Manuais & 880,00 & $105.600,00$ & $1.037,00$ & $124.440,00$ & $1.197,00$ & $143.640,00$ \\
\hline C1.Preparo do solo & 150,00 & $18.000,00$ & 0,00 & 0,00 & 0,00 & 0,00 \\
\hline C2.Implantação & 700,00 & $84.000,00$ & 0,00 & 0,00 & 0,00 & 0,00 \\
\hline C3.Tratos culturais & 30,00 & $3.600,00$ & $1.037,00$ & $124.440,00$ & $1.197,00$ & $143.640,00$ \\
\hline D - Insumos & $10.270,00$ & $1.232 .400,00$ & $1.739,00$ & $208.680,00$ & $2.323,00$ & $278.760,00$ \\
\hline D1. Fertilizantes & $2.770,00$ & $332.400,00$ & 603,00 & $72.360,00$ & 500,00 & $60.000,00$ \\
\hline D2.Fitoss anitário & 0,00 & 0,00 & 727,00 & $87.240,00$ & $1.514,00$ & $181.680,00$ \\
\hline D3.Herbicidas & 0,00 & 0,00 & 204,00 & $24.480,00$ & 96,00 & $11.520,00$ \\
\hline D4.Monitoramento de insetos & 0,00 & 0,00 & 25,00 & $3.000,00$ & 25,00 & $3.000,00$ \\
\hline D5.Mudas de macieira & $7.500,00$ & $900.000,00$ & 150,00 & $18.000,00$ & 150,00 & $18.000,00$ \\
\hline D6.Outros & 0,00 & 0,00 & 30,00 & $3.600,00$ & 38,00 & $4.560,00$ \\
\hline E- Administração & $1.263,00$ & $151.560,00$ & $1.263,00$ & $151.560,00$ & $1.263,00$ & $151.560,00$ \\
\hline E1.Adminis trador e auxiliares & 720,00 & $86.400,00$ & 720,00 & $86.400,00$ & 720,00 & $86.400,00$ \\
\hline E2.Agrônomo próprio e visitas & 180,00 & $21.600,00$ & 180,00 & $21.600,00$ & 180,00 & $21.600,00$ \\
\hline E3.Contabilidade e escritório & 120,00 & $14.400,00$ & 120,00 & $14.400,00$ & 120,00 & $14.400,00$ \\
\hline E4.Viagens & 230,00 & $27.600,00$ & 230,00 & $27.600,00$ & 230,00 & $27.600,00$ \\
\hline E5.Depreciação e benfeitorias & 13,00 & $1.560,00$ & 13,00 & $1.560,00$ & 13,00 & $1.560,00$ \\
\hline Custo Total (R\$/ha/ano) & $19.040,00$ & $2.284 .800,00$ & $4.855,00$ & $582.600,00$ & $6.006,00$ & $720.720,00$ \\
\hline
\end{tabular}

Fonte: ABPM/Relatório Agrianual (2006)/Produtores

Os gastos financeiros iniciais com uma cultura permanente são passíveis de imobilização já que não ocorre o desenvolvimento de frutos, nesta fase. Portanto para identificar o que seria investimento no caso da maçã e como pode ser visualizado na Tabela 12, tomou-se por base os gastos dos três primeiros anos do pomar, sendo o ano de implantação e mais dois anos seguintes, pois é este o período que há produção da fruta mas em pequena quantidade, uma vez que as plantas ainda não são consideradas adultas. Após este período todos os gastos provenientes da manutenção do pomar serão considerados como custos e despesas. 
VICENZI, R.K.F. et al. Rentabilidade e lucratividade das culturas temporárias e permanentes. PUBVET, Londrina, V. 6, N. 9, Ed. 196, Art. 1313, 2012.

$\mathrm{Na}$ Tabela 12 encontram-se resumidamente descritos os gastos iniciais para implantação de um hectare de pomar, onde são contempladas as atividades de construção de espaldeiras, as operações mecanizadas e manuais, os insumos, e demais despesas operacionais. No item que se refere à construção de espaldeiras, faz parte todo o material, como palanques de madeira, âncoras de metal, arame liso, entre outros e, também, a mão de obra necessária para o desenvolvimento da atividade.

Nas operações mecanizadas estão concentrados os gastos com o preparo do solo, caracterizado pela subsolagem, aração e limpeza, e os gastos com a pulverização e transportes de insumos. $E$, nas operações manuais, está a implantação do pomar, propriamente dita, onde são compostas pelas atividades de marcação do pomar, coveamento, plantio, arqueamento, e alguns tratos culturais, como pulverização e roçada.

No item insumos, percebe-se que o valor mais expressivo é o resultante das mudas de macieiras utilizadas para a formação do pomar (plantio). São necessárias em média 2.500 mudas na implantação de um hectare e, poderá haver a possibilidade de replantio de algumas, pois estas podem não se desenvolver. Compõem este item, também, os adubos e fertilizantes, os defensivos agrícolas, e as fitas para arqueamento.

O valor total de cada ano que comporta a fase de implantação do pomar e os dois primeiros anos após são somados e o resultado, é classificado como Ativo Não Circulante - Imobilizado e terá que ser depreciado.

Segundo Marion (2010, p. 42) "toda a cultura permanente que produz frutos será alvo de depreciação. Por um lado, a árvore produtora não é extraída do solo: seu fruto final é o fruto e não a própria árvore". Portanto, uma macieira produz frutos, mantendo-se a planta intacta. Ainda continua Marion (2010) esclarecendo que a depreciação passa a incidir sobre a cultura depois de formada (nunca em formação, inclusive, a partir da primeira colheita plena. Ou seja, com o valor de $\mathrm{R} \$ 3.588 .120,00$ (três milhões, quinhentos e oitenta e oito mil, cento e vinte reais), resultado da soma dos três anos. A taxa de depreciação desse ativo é identificada através de um laudo técnico emitido 
VICENZI, R.K.F. et al. Rentabilidade e lucratividade das culturas temporárias e permanentes. PUBVET, Londrina, V. 6, N. 9, Ed. 196, Art. 1313, 2012.

por Engenheiros Agrônomos, que irão determinar a vida útil do pomar em produção em função da produtividade, inclusive, do tipo de solo, clima, manutenção, mas também em virtude da qualidade e sanidade da planta.

No caso deste estudo de caso, a vida útil do pomar foi estimada em 20 anos, em função de informações recebidas dos produtores. Portanto, o valor anual a ser depreciado do pomar é equivalente a $R \$ 179.406,00$, que divido pelo número de hectares chega-se ao valor de $\mathrm{R} \$ 1.495,00 /$ hectare a título de custo com depreciação, conforme será evidenciado na Tabela 13 que conterá a apuração dos custos e despesas do pomar em questão.

Tabela 13: Custos e despesas - cultura da maçã

\begin{tabular}{|c|c|c|c|c|c|c|c|c|c|}
\hline \multirow{2}{*}{ Discriminação } & \multirow{2}{*}{$\begin{array}{l}\text { Unid de } \\
\text { Medida }\end{array}$} & \multicolumn{6}{|c|}{ CUSTO POR PERÍODO } & \multicolumn{2}{|c|}{ PROJEÇÃO } \\
\hline & & 2007 & $\%$ & 2008 & $\%$ & 2009 & $\%$ & 2010 & $\%$ \\
\hline CUSTOS & & $15.407,00$ & $96 \%$ & $15.678,00$ & $95 \%$ & $16.370,00$ & $94 \%$ & $17.271,00$ & $94 \%$ \\
\hline Insumos & $\mathrm{R} \$$ há & $4.880,00$ & $30 \%$ & $4.978,00$ & $30 \%$ & $5.227,00$ & $30 \%$ & $5.551,00$ & $30 \%$ \\
\hline Mão-de-Obra & R\$/há & $5.517,00$ & $34 \%$ & $5.627,00$ & $34 \%$ & $5.909,00$ & $34 \%$ & $6.275,00$ & $34 \%$ \\
\hline Combustíveis e Lubrificantes & $\mathrm{R} \$$ /há & 915,00 & $6 \%$ & 934,00 & $6 \%$ & 980,00 & $6 \%$ & $1.041,00$ & $6 \%$ \\
\hline Despesas Operacionais & $\mathrm{R} \$$ /há & 583,00 & $4 \%$ & 594,00 & $4 \%$ & 624,00 & $4 \%$ & 663,00 & $4 \%$ \\
\hline Assitência Técnica & $\mathrm{R} \$$ /há & 260,00 & $2 \%$ & 265,00 & $2 \%$ & 278,00 & $2 \%$ & 296,00 & $2 \%$ \\
\hline Seguro de produção & $\mathrm{R} \$$ /há & 554,00 & $3 \%$ & 565,00 & $3 \%$ & 593,00 & $3 \%$ & 629,00 & $3 \%$ \\
\hline Fretes & $\mathrm{R} \$$ /há & 499,00 & $3 \%$ & 509,00 & $3 \%$ & 535,00 & $3 \%$ & 568,00 & $3 \%$ \\
\hline Serviços de manutenção & $\mathrm{R} \$$ há & 121,00 & $1 \%$ & 124,00 & $1 \%$ & 130,00 & $1 \%$ & 138,00 & $1 \%$ \\
\hline Serviços c/ máquinas de terceiros & $\mathrm{R} \$$ há & 238,00 & $1 \%$ & 242,00 & $1 \%$ & 254,00 & $1 \%$ & 270,00 & $1 \%$ \\
\hline Depreciação Pomar & $\mathrm{R} \$ /$ há & $1.495,00$ & $9 \%$ & $1.495,00$ & $9 \%$ & $1.495,00$ & $9 \%$ & $1.495,00$ & $8 \%$ \\
\hline Depreciação dos bens móveis & R\$/há & 345,00 & $2 \%$ & 345,00 & $2 \%$ & 345,00 & $2 \%$ & 345,00 & $2 \%$ \\
\hline DESPESAS & & 687,00 & $4 \%$ & 903,00 & $5 \%$ & $1.033,00$ & $6 \%$ & $1.072,00$ & $6 \%$ \\
\hline INSS s/ Produção Rural & $\mathrm{R} \$ /$ há & 395,00 & $2 \%$ & 598,00 & $4 \%$ & 708,00 & $4 \%$ & 727,00 & $4 \%$ \\
\hline Mão-de-Obra fixa & $\mathrm{R} \$ /$ há & 162,00 & $1 \%$ & 165,00 & $1 \%$ & 173,00 & $1 \%$ & 184,00 & $1 \%$ \\
\hline Despesas Administrativas & $\mathrm{R} \$ /$ há & 130,00 & $1 \%$ & 140,00 & $1 \%$ & 152,00 & $1 \%$ & 161,00 & $1 \%$ \\
\hline TOTAL & R\$/há & $16.094,00$ & $100 \%$ & $16.581,00$ & $100 \%$ & $17.403,00$ & $100 \%$ & $18.343,00$ & $100 \%$ \\
\hline
\end{tabular}

Fonte: ABPM/Relatório Agrianual (2006)/Produtores

Da mesma forma que foi demonstrada na cultura do alho e da soja, apresenta-se a Tabela 13 contemplando os custos e despesas relativos a um hectare de pomar de macieiras, onde serão ressaltados alguns itens que a compõem. Os insumos, por exemplo, nota-se que este item e o item da mão de obra são os mais representativos quando comparados com o todo.

Os insumos representam todo o trato cultural necessário para o desenvolvimento de uma fruta de qualidade. Podem ser citados, neste caso, os 
VICENZI, R.K.F. et al. Rentabilidade e lucratividade das culturas temporárias e permanentes. PUBVET, Londrina, V. 6, N. 9, Ed. 196, Art. 1313, 2012.

defensivos agrícolas necessários para o controle de pragas e doenças, que se não controladas podem comprometer a produção.

Já no que se referem à mão de obra, as atividades de raleio, poda e colheita da maçã é quase, em sua totalidade, realizado de forma manual, o que demanda a contratação de inúmeras pessoas. Neste item, também são contemplados os gastos com encargos sociais, alimentação, transporte e demais despesas que se relacionem a aquela.

Consta na Tabela 13, dentre outros itens, a depreciação do pomar, que conforme já mencionado anteriormente, foi calculado dividindo-se o valor total dos gastos iniciais para a implantação do pomar pela vida útil estimada de 20 anos.

Para se continuar o estudo da rentabilidade e da lucratividade da cultura da maçã são apresentados na Tabela 14, os preços médios recebidos pelo quilo da fruta:

Tabela 14: Preço médio praticado - cultura da maçã

\begin{tabular}{c|c|c|c|c}
\hline & 2007 & 2008 & 2009 & $2010(*)$ \\
\hline Preço Médio Recebido/quilo & $\mathrm{R} \$ 0,55$ & $\mathrm{R} \$ 0,63$ & $\mathrm{R} \$ 0,70$ & $\mathrm{R} \$ 0,70$ \\
\hline
\end{tabular}

Fonte: Informações disponibilizadas pelos produtores

A Tabela 14 apresenta os preços médios recebidos pelos produtores referente às safras 2007 à 2009 e a projeção para 2010. Esses preços referem-se à comercialização da fruta in natura, sem qualquer tipo de processamento. A fruta é retirada do pomar e entregue há uma empresa embaladora que fará o armazenamento, o processamento, a embalagem e realizará a comercialização dos frutos.

Esses valores, vale ressaltar, são resultado de uma pesquisa realizada com produtores da região que entregaram sua fruta à grandes empresas do município, e receberam desta os valores demonstrados na Tabela 14. Importante destacar, que a qualidade, a sanidade da fruta e a colheita 
VICENZI, R.K.F. et al. Rentabilidade e lucratividade das culturas temporárias e permanentes. PUBVET, Londrina, V. 6, N. 9, Ed. 196, Art. 1313, 2012.

realizada no tempo certo, proporcionam remuneração maior ao produtor e ao embalador.

Após se ter conhecimento dos preços que possivelmente um produtor receberia pela venda do seu produto e as variáveis para se atingir essa remuneração, elaborou-se a Tabela 15 que demonstra uma DRE e nela está contida a receita resultante. Esse valor foi encontrado através da multiplicação do preço médio (Tabela 14) pela produtividade estimada de $40 \mathrm{t} / \mathrm{ha} / \mathrm{ano}$, a qual está publicada no Relatório Agrianual 2006:

Tabela 15: Demonstração do Resultado do Exercício - cultura da maçã

\begin{tabular}{l|r|r|r|r}
\hline & \multicolumn{1}{|c|}{$\mathbf{2 0 0 7}$} & \multicolumn{1}{c|}{$\mathbf{2 0 0 8}$} & \multicolumn{1}{c|}{$\mathbf{2 0 0 9}$} & \multicolumn{1}{c}{$\mathbf{2 0 1 0}$} \\
\hline RECEITA BRUTA & $\mathbf{2 . 6 4 0 . 0 0 0 , 0 0}$ & $\mathbf{3 . 0 2 4 . 0 0 0 , 0 0}$ & $\mathbf{3 . 3 6 0 . 0 0 0 , 0 0}$ & $\mathbf{3 . 3 6 0 . 0 0 0 , 0 0}$ \\
(-) Deduções Receita Bruta & $(60.720,00)$ & $(69.552,00)$ & $(77.280,00)$ & $(77.280,00)$ \\
(INSS) & $2.579 .280,00$ & $2.954 .448,00$ & $3.282 .720,00$ & $3.282 .720,00$ \\
RECEITA LÍQUIDA & $(1.848 .840,00)$ & $(1.881 .360,00)$ & $(1.964 .400,00)$ & $(2.072 .520,00)$ \\
(-) Custo Produto Vendido & $\mathbf{7 3 0 . 4 4 0 , 0 0}$ & $\mathbf{1 . 0 7 3 . 0 8 8 , 0 0}$ & $\mathbf{1 . 3 1 8 . 3 2 0 , 0 0}$ & $\mathbf{1 . 2 1 0 . 2 0 0 , 0 0}$ \\
LUCRO BRUTO & $(82.440,00)$ & $(108.360,00)$ & $(123.960,00)$ & $(128.640,00)$ \\
(-) Despesas Oper/Administ & $\mathbf{6 4 8 . 0 0 0 , 0 0}$ & $\mathbf{9 6 4 . 7 2 8 , 0 0}$ & $\mathbf{1 . 1 9 4 . 3 6 0 , 0 0}$ & $\mathbf{1 . 0 8 1 . 5 6 0 , 0 0}$ \\
\hline LUCRO BRUTO & & &
\end{tabular}

Na DRE apresentada na Tabela 15, percebe-se que o ano de 2007 teve um resultado inferior se comparado com as outras safras. Isso ocorreu, segundo os produtores, em virtude dos preços baixos ocasionados, principalmente, por uma "super safra", ou seja, houve uma demanda muito grande de produto.

Nas deduções das receitas está demonstrado o cálculo referente ao INSS sobre a Produção Rural, estabelecido pela legislação em 2,3\%, pois está se tratando de produtor pessoa física. $E$, demais tributos, como ICMS, por exemplo, no caso da maçã este imposto está isento, mesmo que a maçã seja comercializada para outros estados da federação.

Tendo ciência das receitas, das despesas e dos custos serão desenvolvidos a seguir os cálculos para evidenciação da rentabilidade e da 
VICENZI, R.K.F. et al. Rentabilidade e lucratividade das culturas temporárias e permanentes.

PUBVET, Londrina, V. 6, N. 9, Ed. 196, Art. 1313, 2012.

lucratividade proporcionadas pela cultura da maçã, através dos cálculos de VPL, TIR e Ebitda.

\subsubsection{Rentabilidade e lucratividade}

Com base em todas as variáveis da cultura da maçã apuradas e demonstradas anteriormente, forão calculados o VPL, a TIR e o Ebitda, através do fluxo de caixa líquido da cultura da maçã. Este se encontra demonstrado na Figura 3:

\begin{tabular}{|c|c|c|c|c|c|c|}
\hline & $\mathbf{A}$ & B & C & $\mathrm{D}$ & $E$ & $\mathbf{F}$ \\
\hline 1 & Safra & Investime nto & Receitas & Custos & Despesas & $\begin{array}{c}\text { Fluxo de Caixa } \\
\text { Líquido } \\
\end{array}$ \\
\hline 2 & 0 & $(3.588 .120,00)$ & & & & $(3.588 .120,00)$ \\
\hline 3 & 2007 & & $2.640 .000,00$ & $(1.848 .840,00)$ & $(143.160,00)$ & $648.000,00$ \\
\hline 4 & 2008 & & $3.024 .000,00$ & $(1.881 .360,00)$ & $(177.912,00)$ & $964.728,00$ \\
\hline 5 & 2009 & & $3.360 .000,00$ & $(1.964 .400,00)$ & $(201.240,00)$ & $1.194 .360,00$ \\
\hline 6 & 2010 & & $3.360 .000,00$ & $(2.072 .520,00)$ & $(205.920,00)$ & $1.081 .560,00$ \\
\hline 7 & \multicolumn{5}{|c|}{ Taxa mínima de atratividade considerada: } & $10 \%$ \\
\hline 8 & & & & & & \\
\hline 9 & & & \multicolumn{2}{|c|}{$=\mathrm{VPL}(\mathrm{F} 7 ; \mathrm{F} 3: \mathrm{F} 6)+\mathrm{B} 2$} & \multicolumn{2}{|c|}{$=$ TIR(F2:F6;F7) } \\
\hline 10 & & & VPL $=$ & $(565.672,84)$ & TIR $=$ & $3 \%$ \\
\hline
\end{tabular}

Figura 3: Fluxo de Caixa Líquido, Cálculo do VPL e da TIR

É notável que o resultado do cálculo do VPL apresentado na Figura 3 foi negativo, porém o saldo do fluxo de caixa líquido em todas as safras foi positivo, o que leva a acreditar que pode ter sido consequência da TMA, que foi estabelecida em 10\%, estar acima do que a cultura da maçã teria de rentabilidade.

Novamente pode ser visualizada na Figura 3 uma comprovação de que existe retorno financeiro na cultura maçã, porém abaixo da TMA estabelecida para este estudo de caso. A TMA utilizada para os cálculos de rentabilidade e lucratividade foi de $10 \%$, mas, conforme pode ser visto, a TIR resultou em $3 \%$. 
VICENZI, R.K.F. et al. Rentabilidade e lucratividade das culturas temporárias e permanentes. PUBVET, Londrina, V. 6, N. 9, Ed. 196, Art. 1313, 2012.

Calculados o VPL e a TIR, parte-se para a apresentação do Ebitda e, sendo assim, para a identificação da lucratividade através dele. Na Tabela 16, o Ebitda da cultura da maçã é demonstrado:

Tabela 16: Demonstração do Resultado do Exercício - Ebitda Maçã

\begin{tabular}{l|r|r|r|r}
\hline & \multicolumn{1}{|c|}{$\mathbf{2 0 0 7}$} & \multicolumn{1}{c|}{$\mathbf{2 0 0 8}$} & \multicolumn{1}{c}{$\mathbf{2 0 0 9}$} & \multicolumn{1}{c}{$\mathbf{2 0 1 0}$} \\
\hline RECEITA BRUTA & $\mathbf{2 . 6 4 0 . 0 0 0 , 0 0}$ & $\mathbf{3 . 0 2 4 . 0 0 0 , 0 0}$ & $\mathbf{3 . 3 6 0 . 0 0 0 , 0 0}$ & $\mathbf{3 . 3 6 0 . 0 0 0 , 0 0}$ \\
(-) Deduções Receita Bruta & $(60.720,00)$ & $(69.552,00)$ & $(77.280,00)$ & $(77.280,00)$ \\
(INSS) & $2.579 .280,00$ & $2.954 .448,00$ & $3.282 .720,00$ & $3.282 .720,00$ \\
RECEITA LÍQUIDA & $(1.628 .040,00)$ & $(1.660 .560,00)$ & $(1.743 .600,00)$ & $(1.851 .720,00)$ \\
(-) Custo Produto Vendido & $\mathbf{9 5 1 . 2 4 0 , 0 0}$ & $\mathbf{1 . 2 9 3 . 8 8 8 , 0 0}$ & $\mathbf{1 . 5 3 9 . 1 2 0 , 0 0}$ & $\mathbf{1 . 4 3 1 . 0 0 0 , 0 0}$ \\
LUCRO BRUTO & $(82.440,00)$ & $(108.360,00)$ & $(123.960,00)$ & $(128.640,00)$ \\
(-) Despes as Oper/Administ & $\mathbf{8 6 8 . 8 0 0 , 0 0}$ & $\mathbf{1 . 1 8 5 . 5 2 8 , 0 0}$ & $\mathbf{1 . 4 1 5 . 1 6 0 , 0 0}$ & $\mathbf{1 . 3 0 2 . 3 6 0 , 0 0}$ \\
EBITDA/LUCRO OP. AJUSTADO & $(220.800,00)$ & $(220.800,00)$ & $(220.800,00)$ & $(220.800,00)$ \\
(-) Despes as escriturais & $\mathbf{6 4 8 . 0 0 0 , 0 0}$ & $\mathbf{9 6 4 . 7 2 8 , 0 0}$ & $\mathbf{1 . 1 9 4 . 3 6 0 , 0 0}$ & $\mathbf{1 . 0 8 1 . 5 6 0 , 0 0}$ \\
\hline LUCRO BRUTO & & &
\end{tabular}

$\mathrm{Na}$ Tabela 16, onde consta a DRE calculada conforme estabelecida pelo método do Ebitda, a lucratividade apresenta-se maior, como ocorreu, também, nas culturas do alho e da soja. E, conforme especificado anteriormente, isso ocorre porque as despesas que não necessitam de desembolso de caixa, não fazem parte do cálculo do Ebitda ou Lucro Operacional Ajustado.

$\mathrm{Na}$ Tabela 17 é realizado um comparativo entre as lucratividades apresentadas na duas DREs:

Tabela 17: Comparativo entre os resultados das DREs - cultura da maçã

\begin{tabular}{l|r|r|r|r}
\hline & \multicolumn{1}{|c|}{$\mathbf{2 0 0 7}$} & \multicolumn{1}{c|}{$\mathbf{2 0 0 8}$} & \multicolumn{1}{c}{$\mathbf{2 0 0 9}$} & \multicolumn{1}{c}{$\mathbf{2 0 1 0}$} \\
\hline Receita Líquida & $2.579 .280,00$ & $2.954 .448,00$ & $3.282 .720,00$ & $3.282 .720,00$ \\
Lucro líquido & $648.000,00$ & $964.728,00$ & $1.194 .360,00$ & $1.081 .560,00$ \\
Lucratividade & $25 \%$ & $33 \%$ & $36 \%$ & $33 \%$ \\
Lucro Ebitda & $868.800,00$ & $1.185 .528,00$ & $1.415 .160,00$ & $1.302 .360,00$ \\
Lucratividade Ebitda & $34 \%$ & $40 \%$ & $43 \%$ & $40 \%$ \\
Variação da Lucratividade & $9 \%$ & $7 \%$ & $7 \%$ & $7 \%$ \\
\hline
\end{tabular}


VICENZI, R.K.F. et al. Rentabilidade e lucratividade das culturas temporárias e permanentes.

PUBVET, Londrina, V. 6, N. 9, Ed. 196, Art. 1313, 2012.

Considerando os resultados apresentados na DRE e na DRE que contempla o Ebitda nota-se que a variação de lucratividade está em 7\%, apenas no ano de 2007 a variação é um pouco maior. Portanto, quando as depreciações são retiradas do cálculo para apuração do lucro a lucratividade da cultura torna-se mais atrativa.

\section{CONCLUSÃO}

Este trabalho teve como objetivo desenvolver um estudo que se identifica as particularidades e características pertinentes às culturas temporárias e permanentes e, com base em dados econômicos e financeiros proporcionados por três culturas, foram realizados cálculos para evidenciar qual é a rentabilidade e a lucratividade de cada uma.

As culturas temporárias e permanentes diferenciam-se em vários aspectos. Os frutos de uma macieira, por exemplo, ocorre várias vezes, pois a planta possui vida longa e produção por muitos anos, enquanto lavouras de alho e soja proporcionam apenas uma colheita. As contabilizações e a identificação de custos e despesas, também foram demonstrados em cada cultura.

No que se refere à cultura da maçã, por exemplo, os gastos financeiros iniciais dispendidos para a implantação e formação do pomar deverão integrar o Ativo Não Circulante - Imobilizado e este deverá sofrer depreciação de acordo com a vida útil estimada para as plantas de macieiras.

Outro fator fundamental que foi identificado durante a realização deste trabalho é a influência que a agricultura sofre com fatores de clima, solo, mercados, entre outros. No caso da soja, por exemplo, que no Rio Grande do Sul, na safra de 2006 foi prejudicada por uma estiagem de grandes proporções e a maçã, em 2006 a safra foi recorde e consequentemente o seu valor comercial minimizado. Os produtores de alho, por sua vez, sofrem com as importações de países como a China e a Argentina, o que faz com que se trabalhe com preços menores para poder competir. 
VICENZI, R.K.F. et al. Rentabilidade e lucratividade das culturas temporárias e permanentes. PUBVET, Londrina, V. 6, N. 9, Ed. 196, Art. 1313, 2012.

Mesmo diante de todas essas dificuldades e intempéries os produtores continuam apostando nas três culturas e, por isso, se torna fundamental identificar qual delas é mais rentável e qual resulta em uma lucratividade satisfatória.

Procurou-se demonstrar, na execução deste trabalho, conceitos e características à atividade rural, enfatizando a importância da administração e da contabilidade rural para o gerenciamento das atividades. Com ferramentas específicas como planejamento e orçamento financeiro o produtor pode antever custos e despesas e poder, dessa forma, melhorar o desempenho da propriedade.

Para a comprovação da viabilidade dos projetos, foi desenvolvido um estudo de caso, onde se procurou alocar as receitas, os custos e as despesas envolvidas no cultivo das culturas e, através desses dados ter condições de mensurar qual é a rentabilidade e a lucratividade, utilizando os métodos de VPL, TIR e Ebitda. Ressalta-se, que o estudo concentrou-se em quatro anos agrícolas, sendo três já ocorridos e um projetado.

Neste contexto, a cultura do alho apresentou-se a mais rentável, porém com uma lucratividade um pouco mais baixa que as culturas da soja e da maçã. Para esses cálculos de VPL foi estabelecida uma TMA de 10\% para cada cultura, e como resultado a cultura do alho e da soja apresentaram VPL positivo, contrario da maçã. Porém, há de se considerar que a maçã apresentou uma TIR de 3\%, o que sugestiona que se tem rentabilidade, porém abaixo da TMA estabelecida.

A TIR encontrada para a cultura do alho foi de $26 \%$, e para a cultura da soja foi de $38 \%$, ambas acima da TMA e, portanto, rentáveis.

No que se refere à análise da lucratividade com a utilização do Ebitda verificou-se que os gastos que não demandam desembolso de recursos são significativos e podem determinar uma lucratividade maior quando retirados da apuração.

Conclui-se com este trabalho que para o estudo da rentabilidade e a lucratividade das culturas temporárias e permanentes devem-se considerar 
VICENZI, R.K.F. et al. Rentabilidade e lucratividade das culturas temporárias e permanentes. PUBVET, Londrina, V. 6, N. 9, Ed. 196, Art. 1313, 2012.

variáveis que afetam diretamente o cultivo e, o produtor, na hora de decidir em qual cultura investir deverá levar em consideração os métodos apresentados nesta amostragem, mas, também, identificar antecipadamente, qual o investimento inicial que estará disposto a arcar.

\section{REFERÊNCIAS BIBLIOGRÁFICAS}

ANCELES, Pedro Einstein dos Santos. Manual de Tributos da Atividade Rural. São Paulo: Atlas, 2001.

ASSAF NETO, Alexandre. Estrutura e análise de balanço. 7a ed. São Paulo: Atlas, 2002. . Finanças Corporativas e valor. São Paulo: Atlas, 2003.

ABPM, Associação Brasileira de Produtores de Maçã. Caderno 2005.

ABPM, Associação Brasileira de Produtores de Maçã. Caderno 2009.

BATALHA, Mário Otávio (coord.). Gestão agroindustrial. 3a ed. São Paulo: Atlas, 2001.

BONATO, E. R.; BONATO, A L. V. A soja no Brasil: história e estatística. Londrina: EMBRAPACNPSO, 1987.

BRASIL. Instituto Nacional do Seguro Social e Serviço Nacional e Aprendizagem Rural. Manual de orientação da Previdência Social na área rural. Brasília: INSS/SENAR, 2003.

BRASIL. Decreto no 3.000, de 26 de março de 1999. Regulamenta a tributação, fiscalização, arrecadação e administração do Imposto sobre a Renda e Proventos de Qualquer Natureza. Disponível em: <http://www.receita.fazenda.gov.br/Legislacao/RIR/default.htm>. Acesso em: out. 2010.

BRASIL. Medida Provisória no 131, de 25 de setembro de 2003. Estabelece normas para o plantio e comercialização da produção de soja da safra de 2004, e dá outras providências. Disponível em: <https://www.planalto.gov.br/ccivil_03/MPV/Antigas_2003/131.htm.> Acesso em: 25 out 2010 .

CAMARGO, P.B.C.D. O alho: uma planta com o futuro garantido no mercado nacional. $2^{\mathrm{a}}$ ed. São Paulo: Cone Editora, 1985.

CREPALDI, Silvio Aparecido. Contabilidade rural: uma abordagem decisorial. 6a ed. São Paulo: Atlas, 2011.

EMBRAPA, Empresa Brasileira de Pesquisa Agropecuária. Cultura do alho. Brasília: EmbrapaSPI, 1993.

EMBRAPA, Empresa Brasileira de Pesquisa Agropecuária. Recomendações técnicas para o cultivo da soja. Brasília: Embrapa, 1993.

EMBRAPA, Empresa Brasileira de Pesquisa Agropecuária. Cultura da maçã. Brasília: EmbrapaSPI, 1994. 
EMBRAPA, Empresa Brasileira de Pesquisa Agropecuária. Criação de empregos pelo complexo agroindustrial da soja. Londrina: Embrapa soja, 2004.

EPAGRI, Empresa de Pesquisa Agropecuária e Extensão Rural de Santa Catarina.

Orientações Técnicas para a produção de alho em Santa Catarina. Florianópolis:

GMC/Epagri, 2002.

EPAGRI, Empresa de Pesquisa Agropecuária e Extensão Rural de Santa Catarina. CEPA, Centro de Socioeconomia e Planejamento Agrícola. Síntese Anual da Agricultura de Santa

Catarina 2006-2007. Florianopólis, SC.

EPAGRI, Empresa de Pesquisa Agropecuária e Extensão Rural de Santa Catarina. CEPA, Centro de Socioeconomia e Planejamento Agrícola. Síntese Anual da Agricultura de Santa

Catarina 2009-2010. Florianopólis, SC.

EPAGRI. Disponível em: www.epagri.rct-sc.com.br. Acessado em: set/out/nov 2007.

GUTH, Sérgio Cavagnoli; PINTO, Marcos Moreira. Desmistificando a produção de textos

científicos com os fundamentos da metodologia científica. São Paulo: Scortecci, 2007.

IBGE - Instituto Brasileiro de Geografia e Estatística. Disponível em: www.ibge.gov.br.

Acessado em: set/out 2007.

INSTITUTO CEPA S/C. Disponível em: www.icepa.gov.br. Acessado em: out/nov 2007.

KASSAI, José Roberto; KASSAI, Silvia; SANTOS, Ariovaldo dos; ASSAF NETO, Alexandre. Retorno de Investimento: abordagem matemática e contábil do lucro empresarial. $2^{\mathrm{a}}$ ed. São Paulo: Atlas, 2000.

LUCINI, Marco Antônio. Alho - Preços Médios Recebidos de 1999 a 2010. ANAPA, Associação Nacional de Produtores do Alho. Disponível em:

<http://www.anapa.com.br/principal/images/stories/importacoes/recebidos.pdf > Acesso em: 20 ago 2010.

LUCINI, Marco Antonio. Alho: manual prático de produção. Curitibanos: Epagri, 2003.

MAPA. Ministério da Agricultura, Pecuária e Abastecimento. Disponível em: www.mapa.gov.br. Acessado em: set/out 2007.

MAPA. Ministério da Agricultura, Pecuária e Abastecimento. AGE, Assessoria de Gestão Estratégica. Projeções do Agronegócio. Brasil 2009/2010 a 2019/2020. Brasilia:DF, junho de 2010.

MARCONI, Marina de Andrade; LAKATOS, Eva Maria. Técnicas de Pesquisa: planejamento e execução de pesquisas, amostragens e técnicas de pesquisas, elaboração, análise e interpretação de dados. $3^{a}$ ed. São Paulo: Atlas.

MARION, José Carlos. Contabilidade Rural: contabilidade agrícola, contabilidade da pecuária, imposto de renda pessoa jurídica. 12 ed. São Paulo: Atlas, 2010.

MARTINS, Eliseu. Contabilidade de custos: inclui o ABC. 9a ed. São Paulo: Atlas, 2003.

MOTTA, Regis da Rocha; CALÔBA, Guilherme Marques. Análise de Investimentos: tomada de decisão em projetos industriais. $1^{a}$ ed. $4^{a}$ reimpressão. São Paulo: Atlas, 2006. 
RELATÓRIO AGRIANUAL 2006. Anuário da Agricultura Brasileira. Instituto FNP, 2006.

RIO GRANDE DO SUL. Decreto no 37.699, de 26 de agosto de 1997. Aprova o Regulamento do Imposto sobre Operações Relativas à Circulação de Mercadorias e sobre Prestações de Serviços de Transporte Interestadual e Intermunicipal e de Comunicação (RICMS). Disponível em: <http://www.legislacao.sefaz.rs.gov.br/Site/Search.aspx?TxtBusca=Decreto\%2037.699> Acesso em: 7 out. 2010.

RIO GRANDE DO SUL. Decreto no 44.096, de 07 de novembro de 2005. Modifica o Regulamento do Imposto sobre Operações Relativas à Circulação de Mercadorias e sobre Prestações de Serviços de Transporte Interestadual e Intermunicipal e de Comunicação (RICMS). Disponível em: <http://www.legislacao.sefaz.rs.gov.br/Site/Search.aspx>. Acesso em: out. 2010.

SOZO, José. Estudo sobre a cultura da maçã no Rio Grande do Sul e perspectiva de crescimento. Vacaria: AGAPOMI, 2000.

VASCONCELOS, Yumara Lúcia. Revista Brasileira de Contabilidade, Brasília, ano 31, n. 136, p.38-47, jul/ago/2002.

ZAFFANI, Carlos A EBITDA: virtudes e defeitos. Publicação em 10/02/2005. Disponível em: <http://www.calcgraf.com.br/article.php?recid=81>. Acesso em. agosto de 2010. 